\title{
Adaptive measurements of urban runoff quality
}

Brandon P. Wong, Branko Kerkez, Ph.D.

Department of Civil and Environmental Engineering, University of Michigan, Ann Arbor.

\begin{abstract}
:
An approach to adaptively measure runoff water quality dynamics is introduced, focusing specifically on characterizing the timing and magnitude of urban pollutographs. Rather than relying on a static schedule or flow-weighted sampling, which can miss important water quality dynamics if parameterized inadequately, novel Internet-enabled sensor nodes are used to autonomously adapt their measurement frequency to real-time weather forecasts and hydrologic conditions. This dynamic approach has the potential to significantly improve the use of constrained experimental resources, such as automated grab samplers, which continue to provide a strong alternative to sampling water quality dynamics when in-situ sensors are not available. Compared to conventional flow- or time-weighted sampling schemes, which rely on preset thresholds, a major benefit of the approach is the ability to dynamically adapt to features of an underlying hydrologic signal. A $28 \mathrm{~km}^{2}$ urban watershed was studied to characterize concentrations of total suspended solids (TSS) and total phosphorus. Water quality samples were autonomously triggered in response to features in the underlying hydrograph and real-time weather forecasts. The study watershed did not exhibit a strong first flush and intra-event concentration variability was driven by flow acceleration, wherein the largest loadings of TSS and total phosphorus corresponded with the steepest rising limbs of the storm hydrograph. The scalability of the proposed method is discussed in the context of larger sensor network deployments, as well the potential to improving control of urban water quality.

Highlights:

- Studied water quality dynamics of an urban watershed through real-time adaptive sampling.

- An autonomous, Internet-enabled sensor node dynamically adapts to weather forecasts and insitu hydrograph features to control samples of total suspended solids and total phosphorous.

- First flush was not observed and peak loadings were primarily driven by erosion and flashiness.

- Compared to present sampling methods, our framework significantly reduces manpower and resource requirements in the study of water quality dynamics.
\end{abstract}

\section{Keywords:}

Stormwater, sensors, real-time measurements, adaptive sampling, first flush, nutrients, automated sampling, urban stream

This is the author manuscript accepted for publication and has undergone full peer review but has not been through the copyediting, typesetting, pagination and proofreading process, which may lead to differences between this version and the Version record. Please cite this article as doi:10.1002/ 2015WR018013. 


\section{Introduction}

Nonpoint source pollution is a leading cause of surface water impairment in the United States and represents a major management concern as rapid urbanization continues to strain local and regional water resources (Padowski and Jawitz 2012; Rowny and Stewart 2012). The emergence of reliable environmental sensors is poised to transform our understanding of nonpoint source pollution and broader water systems (Hill et al. 2014; Montgomery et al. 2007). In hydrologic studies, new sensors are revealing previously unmeasured dynamics that govern water quality across large watersheds. For example, new optical nitrate sensors are improving the quantification of loads, flow paths, and nutrient dynamics (Hensley, Cohen, Korhnak 2015; Miller et al. 2015; Pellerin et al. 2009). Furthermore, the recent ability to continuously measure turbidity and sediments has challenged existing assumptions of sediment variability, suggesting that nutrient concentrations exhibit complex dynamics that often cannot be attributed to storm features (Métadier and Bertrand-Krajewski 2012).

While these sensor measurements will help to fill critical scientific knowledge gaps, the management of water systems also stands to significantly benefit from an improved understanding of water quality dynamics. Much of urban water quality management is tuned to handle the storm as a whole, seeking to control and treat the cumulative event rather than affect its dynamics. This is accomplished through a variety of green or gray infrastructure solutions 
(Barrett 2005; Roy-Poirier, Champagne, Filion 2010), the choice of which is often based on assumptions of stationarity and few or no measurements. While improved measurements of water quality will help to guide the design and maintenance of these systems, a new generation of intelligent infrastructure (controllable ponds, tanks, weirs, bioswales, etc.) stands to benefit even more from improved quantification of pollutant dynamics. Modern infrastructure will soon route water in real-time to respond to individual storm events (Kerkez et al. 2016; Montestruque and Lemmon 2015; Ocampo-Martinez et al. 2013; Quigley and Brown 2015) to reduce flooding and improve water quality. Such finely grained control will benefit from an equally finely grained understanding of water quality dynamics.

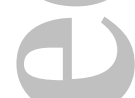

However, the widespread use of in-situ sensors is still limited by costs, high power consumption, and maintenance requirements. Moreover, for many important parameters, such as metals, there are no in-situ sensors to provide such measurements. For emerging contaminants, including viruses and industrial chemicals, in-situ sensors may never become available unless regulations or research drive their development. Automated samplers, which retrieve water samples for subsequent laboratory analysis, may be used to fill these measurement gaps. While they may incur considerable expense for installation, maintenance, and repair (Harmel, Slade, Haney 2010), automated samplers provide a flexible and automated means by which to reduce manhours that would otherwise be required to achieve the same task. 
Advances in wireless communications and data architectures are now significantly reducing the overhead required to deploy environmental sensor networks (Akyildiz et al. 2002; Oliveira and Rodrigues 2011; Rawat et al. 2014), enabling the adaptive and real-time study of water systems. These advances are however not being leveraged to their maximum potential (Corke et al. 2010; Hart and Martinez 2006), as the majority of presently deployed sensor platforms are still used in an off-line fashion. By adapting a study to in-situ conditions and various public sources of realtime data such as weather forecasts or streamflow measurements, the quality of the final experiment stands to significantly improve. This is particularly pertinent in the study of hydrologic systems and nonpoint source water quality, where abrupt changes in water quality due to unanticipated flashy storms often contain critical information about water quality dynamics in watersheds (Fletcher and Deletic 2007).

The goal of this paper is to investigate a scalable approach by which to adaptively measure nonpoint source water quality in urban watersheds with the specific objective of characterizing dynamics (timing and magnitude) of pollutant runoff. An adaptive sampling algorithm is introduced, which executes on sensor nodes and queries local weather forecasts to anticipate state changes in a hydrograph signal. These state changes are then used to guide an online sampling schedule to minimize the resource consumption of a sensor node, while simultaneously 
maximizing the information content of the acquired water quality measurements. The adaptive sampling method is evaluated during the 2014 rain season to study the dynamics and first flush behavior of total phosphorus and total suspended solids (TSS) in an urbanized watershed. While urban nonpoint source water quality is the focus of this paper, the methods presented herein can readily be adapted to a broad suite of other resource-constrained hydrologic and water quality studies.

\section{Background}

\subsection{Problem description}

The study and management of watersheds and drainage networks often hinges upon an accurate detection and characterization of transient events, as the remainder of the system is often in a steady, relatively well-understood state. For many urban hydraulic and hydrologic systems these rapid changes are driven by highly uncertain phenomena, such as precipitation (Langeveld, Liefting, Boogaard 2012; Leecaster, Schiff, Tiefenthaler 2002). Knowledge of water quality dynamics during storm events provides a guiding principle for nonpoint source urban water quality control, which has most recently been brought to the public's attention through the meteoric rise of green infrastructure, particularly across much of the United States (Benedict and McMahon 2006). Beyond green infrastructure, many cities also implement a variety of Best Management Practices (Barbosa, Fernandes, David 2012), several of which are designed to 
route initial flows toward large retention or detention basins for settlement or infiltration. In the American Midwest, some of the most critical water quality measurements include nutrients, particularly runoff-generated phosphorus. While algal blooms and eutrophication are driven by complex dynamics that require both nitrogen and phosphorus, in many freshwater systems, such as the Great Lakes, phosphorous is often the limiting nutrient (Edwards, Conroy, Culver 2005; Rucinski et al. 2010).

A large body of research has shown that runoff pollutant concentrations exhibit highly complex dynamics that depend, among many other factors, on the type of pollutant, intensity of rain events, the physiography of watersheds, local flow regimes, and antecedent dry periods (Eleria and Vogel 2005; Hathaway and Hunt 2011; Langeveld, Liefting, Boogaard 2012; Leecaster, Schiff, Tiefenthaler 2002; McCarthy et al. 2012). One popular concept in urban hydrologic research is the "first flush" of pollutants into streams and rivers (Bach, McCarthy, Deletic 2010; Lee and Bang 2000; Métadier and Bertrand-Krajewski 2012). This effect has been known to occur particularly in urban streams that display leading hysteresis, where the highest concentration of contaminants occurs at the beginning of a storm event, as contaminants are first washed off roads and other impervious surfaces. However, a number of studies have not observed the first flush (Bertrand-Krajewski, Chebbo, Saget 1998; Characklis and Wiesner 1997; Deletic 1998; Métadier and Bertrand-Krajewski 2012), showing that peak pollutant 
concentrations do not always arrive within a small fraction of the initial runoff (Figure 1). While the first flush is an important phenomenon, this initial fraction of runoff may not be the primary or only source of pollutant loadings for some watersheds and chemical constituents. In some streams, high levels of erosion caused by local flow regimes that exceed geomorphically significant levels are a leading cause of suspended sediment and nutrient loads (Hawley and Vietz 2016). For such streams, peak loads of sediments are often correlated to flows rather than a first flush. To that end, there is a need to collect representative measurements of storm-driven water quality dynamics to improve our fundamental understanding of land-use practices on water quality.

\subsection{Instrumentation}

When compared to water flow, water quality remains relatively expensive and difficult to measure (Fletcher and Deletic 2007). Even today, despite advances in telemetry and low-power microcontrollers, a dense spatial coverage of in-situ water quality measurements is still hindered by a lack of reliable and cost-effective sensors. For many important parameters, such as nitrate, the cost and power consumption of sensors inhibit their ubiquitous deployment, while for other parameters, such as phosphorus and phosphates, non-colorimetric or in-situ sensing technologies do not even exist (Horsburgh et al. 2010). Many water quality sensors also consume more energy than the entire remainder of the data acquisition system and require frequent servicing to 
mitigate field effects such as biofouling (Hensley, Cohen, Korhnak 2015; Wagner et al. 2006). As such, maintaining sensor networks to measure water quality across large geographic areas is a resource-intensive task that presently poses a major barrier to the ubiquitous measurements of urban water quality.

When continuous in-situ sensing becomes too expensive or infeasible, field-hardened automated samplers can be used to collect samples, which can be subsequently analyzed in the laboratory for a variety of water quality parameters (e.g. nutrients, metals, solids, bacteria, and other emerging contaminants) (Deletic 1998; Fletcher and Deletic 2007; Gall, Jafvert, Jenkinson 2010; Harmel, Slade, Haney 2010). These units are programmed to pump a sample of water into one of a number of bottles. Depending on the study objectives, these samples usually range from one 20-liter bottle to as many as 24 one-liter bottles. The use of automated samplers presents a set of unique deployment challenges compared to in-situ sensors. In the absence of grid power, the significant mechanical energy required to physically pump samples places a major drain on battery resources. Additionally, samples may need to be refrigerated or chemically treated for preservation depending on the constituents of interest (Harmel et al. 2006; USEPA 1979). As is the case in the use of most other sensors, autosamplers are also plagued by the need to calibrate readings to variability in a stream cross-section. For dissolved constituents, selecting a well- 
mixed site can remedy this variability as a sample at a single point may then be assumed to be representative of the entire stream cross-section.

While one-bottle samplers are a practical means by which to study the composite effects of a storm event, they do not provide insight into the detailed dynamics of an event, which is important if they are to be used as substitutes for continuous, in-situ sensors. When using multiple sample bottles to resolve urban pollutograph dynamics, the limited number of available bottles becomes a major constraint. If the timing, magnitude, and duration of storms are not accurately anticipated, 'wasted' or missed samples often become a common experimental occurrence. Measuring too slowly can entirely miss the dynamics of an underlying pollutograph (Figure 2a). On the other hand, measuring too fast or too early may deplete the number of sample bottles before an event is fully captured, which is particularly common if storms last for multiple days (Figure 2b). To mitigate this, units can be configured to acquire samples if a preset flow threshold is exceeded, after which the hydrograph can be sampled according to predetermined flow- or time-weighted intervals (Gall, Jafvert, Jenkinson 2010; Harmel, King, Slade 2003). However, this strategy may miss important baseflow samples. Also, as storm duration and intensity can be highly variable, setting triggers or intervals to static values may not consistently sample a wide range of storm events. Flow-weighted sampling cannot account for storm intensities that deviate far away from the design storm or have multiple distinct discharge 
peaks (Figure 2c). Furthermore, the number of available bottles may still be depleted before an event is fully captured if the storm lasts longer than expected. While missed baseflow concentrations can sometimes be estimated from samples taken during other dry weather periods (Anderson and Rounds 2010; Beck and Birch 2012), such estimates may be inaccurate since elevated concentrations may occur at the onset of a storm (Horowitz 2009). None of the conventional sampling techniques distinguish between important points of the flow hydrograph, such as the peak and inflection points, which may often contain significant information with regard to the effect of land-use variability on the pollutograph.

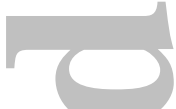

\subsection{Adaptive sampling}

The concept of adapting measurement strategies or detecting events of interest has been introduced broadly in the signal processing and machine learning literature for a variety of applications but has seen limited use in hydrology. Often, adaptive sampling revolves around spatial measurement strategies, where measurements at one location are used to inform locations of new measurements (Singh, Nowak, Ramanathan 2006). The problem can also be extended to the temporal domain, where sampling frequencies are changed during events of interest (Krause et al. 2009). The task of detecting these events falls broadly into the literature of change-point detection (Reeves et al. 2007; Tartakovsky, Nikiforov, Basseville 2014), where a signal is monitored to isolate abrupt state changes or transient events. While few studies couple these two 
objectives, in the case of water quality, adaptive sampling and change-point detection are inherently coupled, as the detection of a hydrograph change must be accompanied by a change in the sampling schedule to resolve the features of the pollutograph. Much of the existing literature on these topics does not explicitly incorporate the physical dynamics or nuances of such phenomenon, which limits their benefit to many real-world experiments.

While automated samplers provide a way to sample many water quality parameters simultaneously, the off-line use of these devices impedes their scalability as an experimental platform. The use of in-situ measurements coupled with real-time data, which is readily afforded by current technologies, has the potential to transform these sampling strategies from static to highly adaptive. For example, Gall et al. (2010) reprogrammed an automated sampler to distribute 20 sampling bottles throughout a storm event. This approach, however, did not consider explicit hydrograph states or weather forecasts, which may cause valuable measurements to be missed. To that end, real-time data processing and adaptive sampling will allow sensing resources to be continuously optimized around site-specific conditions to ensure that measurements are taken at the most informative points.

\section{Methods}


A real-time framework for the adaptive sampling of water quality is presented, which controls automated samplers to minimize the number of sampling bottles required to reconstruct the temporal dynamics of the pollutograph. The method continuously adapts to individual storm events by incorporating real-time weather forecasts and updating a local model of flow conditions to trigger samples in response to hydrograph features rather than predetermined timing or flow thresholds. The technique is designed to be computationally simple enough to be executed efficiently on a field-deployable microcontroller, but can also be readily ported to the cloud or remote servers. The approach (Figure 3) forms an embedded processing chain, leveraging local and remote computational resources to assimilate real-time sensor measurements into a model of local water flow. The core of the architecture is comprised of embedded, remotely-deployed, and internet-connected sensor nodes, which obtain live meteorological forecasts from public web services to persistently update the probability of precipitation in the study area. Measurements from a local depth sensor are continuously fed to a state estimator, which estimates the flow dynamics of the stream. These estimates are then fused with the latest weather forecast and routed to a sampling controller, which determines when the next sample should be taken by the autosampler.

\subsection{State estimation}


207 The state of the hydrograph must first be estimated before water quality measurements can be

208 scheduled. Let the state $x(t)$ denote the flow (or stage) of the hydrograph at time $t$. We assume 209 that the measured flow is corrupted by noise, $\varepsilon(t)$, such that a sensor measurement $y(t)$ is given 210 by:

212 where $\varepsilon(t) \sim N\left(0, \sigma^{2}\right)$ is normally distributed, zero mean. Given the real-world performance of 213 most sensors, the measurement noise can be taken as stationary, with a variance $\sigma^{2}$ that can 214 readily be obtained from manufacturer datasheets or a simple laboratory evaluation.

In most applications, rather than triggering new samples based on the actual flow, it may be 217 more relevant to trigger samples based on the first or second derivatives of the flow, which are 218 indicators of important hydrograph features independent of storm duration and magnitude. For 219 example, it is often of interest to distinguish between the rising or falling limbs of the 220 hydrograph:

$$
\frac{d x}{d t} \geq 0 \text { rising hydrograph limb }
$$

$$
\frac{d x}{d t}<0 \text { falling hydrograph limb. }
$$


222 The first derivative can be used to detect the onset of a storm event or find the hydrograph peak, while the second derivative of the flow $d^{2} x / d t^{2}$ can be used to detect inflection points, which

224 are indicators of precipitation intensity or baseflow conditions. For notational simplicity, let $225 \dot{x}=d x / d t$ and $\ddot{x}=d^{2} x / d t^{2}$. Given the noise in real-world signals, directly differentiating the

226 noisy signal $y$ would only amplify the effects of the noise, thus obscuring any meaningful 227 estimate of derivatives. Thus, an improved estimate of $x$ must first be obtained in real-time 228 before $\dot{x}$ and $\ddot{x}$ can be used to make sampling decisions. This is particularly true in smaller 229 storms, for which changes in flow may be subtle.

We derive a noise-free estimate $\hat{x}(t)$ through a non-parametric kernel smoother (Hastie,

232 Tibshirani, Friedman 2009). For a noisy observation $y_{j}$ at time $t_{j}$ let $\hat{x}\left(t_{j}\right): \mathbb{R}^{n} \rightarrow \mathbb{R}$ be a 233 function that obtains a local estimate of $x_{j}$ through the kernel operation:

$$
\hat{x}\left(t_{j}\right)=\hat{x}_{j}=\frac{\sum_{i=1}^{n} K\left(t_{j}, t_{i}\right) x_{i}}{\sum_{i=1}^{n} K\left(t_{j}, t_{i}\right)}
$$

235 where $K(\cdot)$ is the kernel function and $n$ is the number of observed points to be weighted. Given 236 the normally distributed noise assumption, a good choice of kernel is given by the radial basis 237 function:

$$
K\left(t^{*}, t_{i}\right)=\exp \left(-\frac{\left(t^{*}-t_{i}\right)^{2}}{2 r^{2}}\right)
$$


239 where $r$ is the length-scale parameter. This kernel smoothing operation weighs the importance of 240 neighboring measurements based on their distance (time, in this case) to the measurement of 241 interest. This smoother is ideally suited for the proposed application, as it does not assume that 242 measurements are taken at even time intervals. Furthermore, this state estimator is very 243 computationally efficient, permitting its implementation on computationally-constrained, low244 power microcontroller platforms or data loggers. Once the measured data has been filtered, an 245 estimate of the noise free derivative can be obtained by numerically differentiating the smoothed 246 state.

\subsection{Adaptive sampling algorithm}

249 Once estimates of $x, \dot{x}$, and $\ddot{x}$ have been obtained, the sampling objective becomes to decide when to take the next measurement. This can be accomplished by scheduling a future sensor reading at time $t+t_{s}$, or by changing the sensor sampling frequency to $f_{s}=\left(t_{s}\right)^{-1}$. Often, the sensor used to derive the flow estimates $x(t)$ consumes fewer resources than the sensor used for water quality measurements, as is the case with the automated sampler used in this study. As such, measurements of water height or flow can be made at a higher frequency and used to drive 255 measurements of water quality.

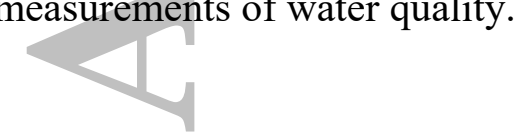


257 A real-time probability of precipitation, obtained in our case by querying the public WeatherUnderground forecast (Weather Underground 2016), is used to trigger the autosampler to take a water quality sample before a storm. This provides a valuable baseflow measurement and safeguards from missing measurements during instances when the hydrograph changes too rapidly or at too small of an amplitude to be detected by flow sensors alone. The sampling

262 algorithm (Figure 4) uses the weather forecast to trigger a sample when the chance of 263 precipitation exceeding $5 \mathrm{~mm}$ within the hour surpasses $10 \%$ (empirically determined based 264 upon an analysis of historical forecasts and the resulting hydrologic response). Samples are then conditions right before a storm, (2) the onset of the hydrograph to detect a potential first flush, (3) the inflection-point of the rising limb of the hydrograph (4) the peak of the hydrograph, (5) 269 the inflection-point of the falling limb of the hydrograph, and (6) the falling limb of the hydrograph as it returns to within $10 \%$ of the pre-storm baseflow. In the case that the weather

271 forecast is erroneous, the initiation of a storm event is also marked when the slope in the 272 hydrograph exceeded $7.5 \mathrm{~m}^{3}$ over 5 minutes, which for our study site corresponded with the minimum observed change in flow from baseflow conditions caused by $5 \mathrm{~mm}$ of precipitation in

274 one hour. The algorithm can also be viewed as a state machine, where samples are triggered 275 during state transitions, as determined by estimates of the flow $x$ and its derivatives. The state 
machine is designed to account for multiple flow regimes (such as delayed surface flows from neighboring slopes), taking additional samples if multiple inflection points or local hydrograph peaks are detected.

\subsection{Study area, sensors, and cyberinfrastructure}

The adaptive sampling algorithm was tested on a sensor node deployed during the 2014 rain season at the outlet of an urban watershed near Ann Arbor, Michigan (Figure 5, Latitude $42^{\circ} 15^{\prime} 53^{\prime \prime}$, Longitude $\left.-83^{\circ} 41^{\prime} 18^{\prime \prime}\right)$. The outlet drains into an end-of-line water quality detention basin located along the Huron River. Ann Arbor's climate is classified as humid continental with severe winters, hot summers, no dry season, and strong seasonality. Annual precipitation is 955 $\mathrm{mm}$ and snowfall is $1450 \mathrm{~mm}$. The study area comprises a $28 \mathrm{~km}^{2}$ catchment that is over $80 \%$ impervious with the large concentration of impervious surfaces located near the centroid of the watershed. By the Richards-Baker flashiness index (Baker et al. 2004), the catchment has a seasonal index of 0.653 , which is relatively high for streams in Michigan.

A sensor node and real-time cyberinfrastructure, whose technical details are described in Wong and Kerkez 2014a and Wong and Kerkez 2014b, were deployed in the northeastern outlet of the watershed. The sensor node is equipped with a low-power microcontroller (ARM Cortex-M3 architecture) and a low-power wireless module (Telit CC864-DUAL) to take advantage of urban 
cellular coverage. For the purposes of this experiment, the node was interfaced with a low-cost, low-power ultrasonic depth sensor (MaxBotix MC7384, 3.1mA at 5VDC) to measure the stage of the hydrograph every five minutes, as well as an automated sampler (ISCO 3700, standby: 10 $\mathrm{mA}$ at 12VDC, sampling: 2000mA at 12VDC) that drew samples from the run of a stream, where channel features were deemed moderate and homogenous (Teledyne Isco 2012). To resolve runoff-driven quality dynamics, a 24-bottle configuration of the automated sampler was used. Weather forecast data was queried every five minutes. For comparison of stage measurements, the node was collocated with a USGS gage (04174518). Upon validation of the stage estimates, the rating curve of this gage was used to derive flow from our depth readings. In this study, this permitted for flow, rather than stage, to be used to trigger the automated sampler.

\subsection{Water quality analysis}

The samples taken the by the automated sampler were analyzed for total phosphorus and TSS according to EPA Methods 365.3 and 160.2, respectively (USEPA 1979). EPA Method 365.3 uses a two-step pretreatment and colorimetric approach to determine total phosphorus concentrations while EPA Method 160.2 determines TSS concentrations by first filtering a sample and drying the non-filterable residue in an oven to a constant weight. Bottles were pretreated and collected within twenty-four hours of each storm event to ensure samples were 
314 properly preserved prior to analysis. TSS was chosen due to its surrogate relationship with many

315 other contaminants including total phosphorus (Grayson et al. 1996; Rügner et al. 2013), which

316 was analyzed due to the study site's proximity to Lake Erie, where loadings of total phosphorus

317 are of interest to the study of algal blooms (Dolan and McGunagle 2005).

318

319 To characterize nutrient dynamics and first flush behavior, lab results for each storm event were 320 analyzed using cumulative mass-volume curve or $M(V)$ curve analysis (Bertrand-Krajewski, 321 Chebbo, Saget 1998; Métadier and Bertrand-Krajewski 2012), which compares the dimensionless ratio (percentage) of the cumulative flow-weighted concentration with the cumulative runoff over the course of a storm event. This analysis permits the water quality 324 dynamics within multiple storm events to be compared by normalizing for factors such as storm duration or quantities of loading. To identify the existence and strength of a first flush, each

$326 \mathrm{M}(\mathrm{V})$ curve was approximated with a power law function:

$$
M(k)=V(k)^{b}
$$

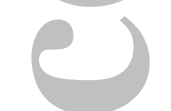

$$
=\frac{\sum_{i=1}^{k} C_{i} Q_{i} \Delta t_{i}}{\sum_{i=1}^{N} C_{i} Q_{i} \Delta t_{i}}=\left(\frac{\sum_{i=1}^{k} Q_{i} \Delta t_{i}}{\sum_{i=1}^{N} Q_{i} \Delta t_{i}}\right)^{b}
$$

$329 \mathrm{k}^{\text {th }}$ sample of a given storm event over which $N$ total samples are taken; $C_{i}, Q_{i}$, and $\Delta t_{i}$ are the 
concentration, discharge, and sampling frequency, respectively, of the $i^{\text {th }}$ sample (BertrandKrajewski, Chebbo, Saget 1998; Métadier and Bertrand-Krajewski 2012). The value of $b$ is inversely proportional to the strength of the first flush (i.e., a value much less than unity, $0 \leq b<$ 0.185 , would correspond to a strong first flush) and the fit is considered satisfactory for $\mathrm{r}^{2}>0.9$ (Bertrand-Krajewski, Chebbo, Saget 1998). For each event, the b-value was estimated by minimizing the least-squares fit between equation (5) and the individual data points.

To characterize the variability of pollutant concentrations between storms, the event mean concentration (EMC) was also calculated. The EMC normalizes the total event load by the total event runoff volume, yielding a flow-weighted average of the pollutant concentration (Langeveld, Liefting, Boogaard 2012; Lee and Bang 2000; Métadier and Bertrand-Krajewski 2012). It has been shown that in urban environments, peak EMC of pollutants in stormwater runoff can be as much as twenty times larger than baseflow EMC during dry weather conditions (Lee and Bang 2000). The EMC was used in this study to quantify the constituent concentrations carried by runoff in comparison to baseflow conditions for each storm event. The influence of other factors to event mean concentrations, such as antecedent dry conditions (Li et al. 2007) and storm intensity (Bertrand-Krajewski, Chebbo, Saget 1998), was also considered in the analysis.

\section{Results}




\subsection{Adaptive sampling algorithm}

During the 2014 deployment season, the adaptive sampling algorithm was evaluated on four storm events (July 1, August 11, August 19, and September 10). Each event was preceded by at least a 48-hour antecedent dry period followed by a storm where at least $5 \mathrm{~mm}$ of precipitation fell within 24 hours (Table 2). The July 1 event was driven by a $9.4 \mathrm{~mm}$ storm over 2 hours with a peak flow $2.78 \mathrm{~m}^{3} / \mathrm{s}$; the August 11 event was driven by a $24 \mathrm{~mm}$ storm over 7 hours, characterized by an initial peak flow of $1.30 \mathrm{~m}^{3} / \mathrm{s}$ followed 2 hours later by a peak flow of 2.01 $\mathrm{m}^{3} / \mathrm{s}$; the August 19 event was driven by a $9.4 \mathrm{~mm}$ storm over 2 hours with peak flow of 4.33 $\mathrm{m}^{3} / \mathrm{s}$; the September 10 event was driven by a $36 \mathrm{~mm}$ storm over 5 hours with an initial peak flow of $4.70 \mathrm{~m}^{3} / \mathrm{s}$ followed 2 hours later by a peak flow of $5.27 \mathrm{~m} / \mathrm{s}$.<smiles>C=CC</smiles>

The state estimator and real-time kernel smoother correctly identified the pertinent flow regimes, triggering the automated sampler within an average of 3.5 minutes (standard deviation $\sigma=3.8$ minutes) to collect water quality samples as dictated by the control logic (Figure 6, example of August 19 event). The relation between the stage $y$, as estimated by the sensor node, and the discharge $Q$ measured by the nearby USGS gage was found to be $Q=0.729(y-32.5)^{2.47}$ and was derived using a least-squares fit $\left(\mathrm{r}^{2}=0.993\right)$. The real-time kernel smoothing operation was important to obtaining accurate state estimates, as directly taking the derivative of the sensor signal yielded a noisy, zero-mean signal that could not be used to determine meaningful changes 
in the hydrograph. Integration of real-time weather forecasts into the control logic ensured that the automated sampler was triggered just before the onset of a storm, allowing for baseflow and background conditions to be decoupled from storm-driven water quality dynamics.

\subsection{Water quality}

Concentrations for both TSS and total phosphorus showed a positive linear correlation with flow $\left(\mathrm{R}^{2}=0.346\right.$ for TSS; $\mathrm{R}^{2}=0.437$ for $\mathrm{TP}$ and standard deviations $\sigma=198.6 \mathrm{mg} / \mathrm{L}$ and $\sigma=0.272$ $\mathrm{mg} / \mathrm{L}$, respectively). Samples taken particularly during peak flows had the highest concentrations and there was no observed hysteresis between peak concentration and peak flow. With the exception of the August $11^{\text {th }}$ event, peak concentrations strictly corresponded with peak flows (Table 2). The 7-hour storm event on August $11^{\text {th }}$ drove two distinct discharge peaks. During this event, the largest concentrations occurred during the first peak while the largest flows occurred during the second. In general, for the storms with multiple distinct hydrograph peaks, the intrastorm hydrograph with the relatively steeper rising limb (larger flow acceleration) had the largest pollutant concentration. This was also seen during the September $10^{\text {th }}$ storm event, which also exhibited two distinct discharge peaks. During this event, the second peak, while relatively larger, was also characterized by a steeper rising limb and higher concentrations.

Temporal comparison of hydrograph and pollutograph peaks showed no discernable leading hysteresis. Similarly, through an $\mathrm{M}(\mathrm{V})$ curve analysis, none of the water quality dynamics could 
be classified as exhibiting a strong first flush. Overall, the $b$-values range from 0.684 to 0.908 and $\mathrm{r}^{2}<0.9$ (Table 1). Six or more samples were collected for each event and M(V) curves were generated using a spline interpolation (Figure 7). Similar M(V) curves were observed for both TSS and total phosphorus. TSS could not be analyzed from the July 1 event as the automated sampler was not initially configured to sample a large enough volume to provide aliquots for TSS analysis.

Peak concentrations of TSS and total phosphorus were neither correlated with rainfall intensity $\left(r^{2}=0.105\right.$ and $r^{2}=0.0277$ for TSS and total phosphorus, respectively) nor antecedent dry weather periods $\left(r^{2}=0.142\right.$ and $r^{2}=0.0841$ for TP and TSS and total phosphorus, respectively). The largest of the storm events (September $10^{\text {th }}$, as measured by stage height and cumulative flow volume) recorded the lowest concentrations of TSS and total phosphorus. Overall, the EMC of total phosphorus was at least three times greater during runoff than during baseflow conditions and the EMC of TSS was at least three times greater (Table 2). For both TSS and total phosphorus, the runoff EMC of each pollutant did not exhibit a linear trend over time.

\section{Discussion}

\subsection{Adaptive sampling}


Compared to conventional flow- or time-weighted sampling schemes, which rely on preset thresholds, a major benefit of the proposed approach is the ability to anticipate and dynamically adapt to features of an underlying hydrologic signal. This is particularly valuable when resolving pollutograph dynamics across a variety of storm durations and intensities, as it ensures that each distinct hydrograph is characterized using a similar number of samples. Depending on the objectives of the study, this enables the ability to resolve flashy events to the same extent as larger events using the same sampling logic. This not only introduces an element of consistency for inter-storm comparisons, but also reduces the occurrence of missed or excessive samples that are common in conventional sampling approaches. In turn, this improves the use of constrained experimental resources.

If storm patterns drive multiple discharge peaks, such as those experienced on August $11^{\text {th }}$ and September $10^{\text {th }}$, the smaller peak or the secondary peak, even if short in duration or magnitude, may carry the majority of the pollutant loadings. The use of a flow-weighted approach may have missed such events if parameterized inadequately. A more dynamic estimation approach, as used in this study, is needed to track not only the flow, but also changes in the underlying hydrologic signal. In more advanced experiments, rather than just triggering baseflow samples, the weather forecast could also be used to anticipate the number and timing of samples. In-situ and real-time sensor readings (such as stage or turbidity) will still be required, however, to adapt to site- 
specific dynamics that cannot be captured by a weather forecast alone. Given the flexibility of our proposed framework, such modifications can be made easily and the sampling logic can be updated in real-time without the need to visit the study site.

The flexibility of the framework proposed in this paper is perhaps its biggest benefit. While our sampling approach focused on site-specific hydrograph features, the sampling logic could be changed relatively easily to enable a suite of novel and uniquely targeted experimental objectives. Sampling strategies could be modified to detect debris or faulty sensors by tuning the length-scale parameter of the kernel in real-time, or by implementing more complex faultdetection algorithms (Zhang, Meratnia, Havinga 2010). Future experiments could also be designed to use distributed rainfall data and measurements from other sensor nodes to optimize sampling around spatial phenomena of interest. For example, sudden changes in flow at upstream sensor nodes could be used to alert downstream nodes or to track a storm as it moves through a region. Additionally, real-time hydrologic models could be used to enable more complex sampling strategies during different seasons. For example, a snowmelt model and a conductivity sensor could be used to guide chlorine sampling during road salting periods. By leveraging an Internet connection, the majority of this control logic could be implemented on off-site computers, improving ease of use by permitting researchers to implement the control logic using systems and languages they are most comfortable with. 
The benefits of adaptive water quality sampling can be achieved at a relatively small overhead. In fact, in their simplest implementation, the methods presented in this study could be readily repeated by simply connecting a cellular modem to the autosampler, relying only on a remote computer and public data (for example, streamflow and precipitation obtained from CUAHSI's Water Data Center (CUAHSI 2016)) to control the sampling schedule. The need to process realtime sensor feeds comes at a slight computational expense, but is well achievable using already existing technologies and data services (Amazon Web Services 2016; InfluxDB 2016). By adding in-situ sensors, such as the low-cost water level sensor used in this study, the capabilities of the automated sampler can be extended even further to enable more responsive and complex sampling strategies. For example, given the observed correlation between TSS and total phosphorus, as well as known correlations between those parameters and turbidity (Grayson et al. 1996; Rügner et al. 2013), an in-situ turbidity sensor could be used to design an adaptive sampling regimen for total phosphorus. Rather than sampling around distinct features of the hydrograph, such a study could focus on sampling around the most uncertain statistical parameters of the regression relationship. This may increase the complexity of the sampling strategy, but it improves the quality of the data input to the regression, and, in turn, the confidence of the statistical relationship. 


\subsection{Water quality}

While the occurrence of a first flush may be variable or specifically associated with large and intense storm events (Barbosa, Fernandes, David 2012), no correlation was found between increasing storm intensity and the likelihood of a strong first flush. Similar conclusions have been drawn in other studies that analyzed loading dynamics of urban runoff (Bach, McCarthy, Deletic 2010; Deletic 1998; Métadier and Bertrand-Krajewski 2012). The lack of an observable first flush in our watershed could be attributed to a number of causes, including the relatively large size of our study area $\left(28 \mathrm{~km}^{2}\right)$. Within our study area, a first flush may have existed in much smaller sub-catchments, as suggested by prior studies (less than $1 \mathrm{~km}^{2}$, see Lee and Bang 2000). However, first flush may not be evident for larger watersheds, particularly if the pollutograph travel times for each sub-catchment superimpose, as their confluence may obscure or widen the concentration profile at the outlet of the larger watershed (Characklis and Wiesner 1997; Sansalone and Cristina 2004). Furthermore, if one specific area of the watershed contributes the major pollutant runoff, its travel time in relation to peak discharge at the outlet of the watershed could impact the perceived first flush dynamics.

In our study watershed, a large concentration of solids would be expected from the dominant, heavily urbanized and impervious surfaces of the watershed, which all exhibit very short travel times and should have contributed to a first flush if it existed. To that end, it is likely that 
erosion, caused by flashy hydrographs or high flows, was the primary driver of water quality in the watershed. Studies have shown that the majority of the phosphorus in runoff is sedimentassociated (Ellison and Brett 2006; Paul and Meyer 2001), but in many highly urbanized watersheds, this may need to be directly confirmed since many management practices are still geared towards treating the first flush (Benedict and McMahon 2006; Wise 2008). The urban areas in our study watershed may thus not be a major source of nutrient runoff. While outside of the scope of this study, a small number of the events were also analyzed for other dissolved pollutants, which also did not exhibit first flush characteristics.

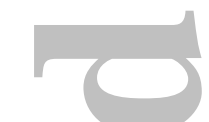

Although peak pollutant loads corresponded with peak flows, this relationship was nuanced, where a higher fraction of contaminants arrived after peak flow rather than before. This has also been seen in prior studies (Métadier and Bertrand-Krajewski 2012). Furthermore, b-values were much greater than 0.185 , indicating a lack of a strong first flush in our study catchment. As such, flow values may need to exceed geomorphically significant levels to begin moving sediment (Booth and Jackson 1997). However, this would need to be studied in detail by augmenting the sampling strategy.

Peak concentrations were also poorly correlated with rainfall intensity and duration of antecedent dry weather periods. While this is contradictory to some studies (Li et al. 2007), it 
has been observed by others (Métadier and Bertrand-Krajewski 2012). The relationship between EMC and rainfall has been generally noted to be weak, suggesting that EMC is likely driven by location- rather than storm-specific features (Gnecco et al. 2005). As such, EMC may not be the best sole measure of water quality characteristics, particularly when studying pollutant dynamics of individual storms. Concentrations for any given event are a complex function of buildup and washoff characteristics (Métadier and Bertrand-Krajewski 2012) and spatial rainfall variability, which thus suggests that any given storm event may exhibit unique concentration magnitudes and temporal characteristics.

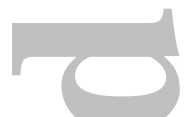

Throughout this study, pollutograph dynamics were driven by variable storm patterns, a number of which contained multiple hydrograph peaks. Low correlations between concentration and discharge were observed and have been similarly reported for other urban catchments (Rees et al. 2006), indicating that concentration may not be fully explained by discharge alone. While lower concentrations of TSS and total phosphorus may have resulted from dilution, caused by increased flows mobilizing more coarse-grained sediments (Tiefenthaler, Schiff, Leecaster 2000), this could not be confirmed consistently across all events. Within storm events with multiple peaks, the peak concentration did not just correspond with the peak flow, but rather with the hydrograph peak that had the steeper rising limb (larger flow acceleration). On an intraevent scale, this suggests that rather than a lag in the pollutograph, as would be suggested by 
$\mathrm{M}(\mathrm{V})$ analysis alone, the concentrations are heavily driven by the hydrograph features. The acceleration of flows may correspond with increased forces exerted on solids, which raise the erosive action on the stream. In our watershed, the "flashiness" of the hydrograph, a well-known symptom of the urban stream syndrome (Walsh et al. 2005), is thus perhaps the best predictor of peak concentrations within an individual event.

Better characterizations of water quality thus demand more spatially dense measurements and an improved understanding of pollutograph dynamics, a task which will be made easier by the adaptive sampling methods presented in this paper. In particular, more samples will be required to determine if a first flush is evident in smaller upstream locations, where the pollutograph may be dominated by runoff from impervious regions, rather than stream dynamics. That said, upscaling the adaptive sampling framework will need to be done carefully, as optimal sampling schedules may likely be guided by site-specific features. Even sites that are very close to one another may exhibit distinctly different pollutograph dynamics. As such, initial measurements and calibrations will likely still need to be carried out on each site, after which the most suitable adaptive sampling strategy can be tuned. A feature-driven approach, such as the one presented here, will form a good starting point to help formulate a site-specific sampling strategy. The proposed adaptive sampling framework will provide a flexible and low-overhead means by 
which to reduce the resources required to investigate the dynamics that are most uncertain at any site.

\section{Conclusions}

Increasing the temporal resolution of measurements will significantly improve our fundamental understanding of water quality dynamics. Understanding these dynamics across various scales can also help decision-making by guiding watershed-specific solutions that strike a balance between local treatment (e.g. green infrastructure), restoration, or end-of-line solutions. Until reliable and cost-effective in-situ sensors are available for most important parameters, multibottle automated samplers will continue to provide a strong alternative to resolving the water quality dynamics of hydrologic systems.

Given real-time notifications and the convenience of using a feature-driven approach to automatically collect samples, the method proposed in this paper could lower barriers for small research groups, agencies or even individuals to now seamlessly maintain large networks of autosamplers (networks of ten or more samplers). The flexibility the framework presented herein not only makes this possible for automated samplers, but also for in-situ sensors that consume a significant amount of power or are limited by reagent availability or electrode duty cycling. 
The lack of an observed first flush in our watershed cautions the implementation of many popular stormwater control measures for improving urban runoff quality. The majority of these systems, such as retention ponds and constructed wetlands are designed to capture a maximum volume of flow (one to two year storms), which is retained for settling while excess flows are released through overflow structures. However, if the inflows to the basin do not exhibit a first flush, the basin may only retain the initial, lower concentration flows, while discharging higher concentrations once storage capacity has been reached.

An exciting paradigm may arise from this realization however: by equipping urban stormwater systems with sensors and controllers (valves, gates, pumps, etc.), it will be possible to maximize the treatment of runoff through real-time control (Kerkez et al. 2016). While this idea will require significant future studies to vet its promise, the site-specific characterization of water quality dynamics (or corresponding proxies), as provided by our approach, will allow controllers to be optimally tuned to individual storm events. For example, a gate could be opened at the beginning of a storm to allow lower-concentration flows to exit the watershed, while closing to capture the highest concentration inflows and retain them as long as possible before the next storm event. Similarly, these solutions could be implemented upstream to reduce the exceedance of geomorphically significant flows, and thus downstream erosion and nutrient loads. These real- 
time systems are presently being constructed in this study watershed and will be evaluated in the future.

\section{Acknowledgements}

We would like to acknowledge the support of the University of Michigan, as well as our collaborators at the Huron River Watershed council for facilitating the deployment of our sensor nodes on the Huron River in Ann Arbor, Michigan. Data and source code, as well as hardware and sensor schematics used to produce the figures in this paper can be obtained by directly contacting the authors or visiting their website (www.tinyurl.com/bkerkez).

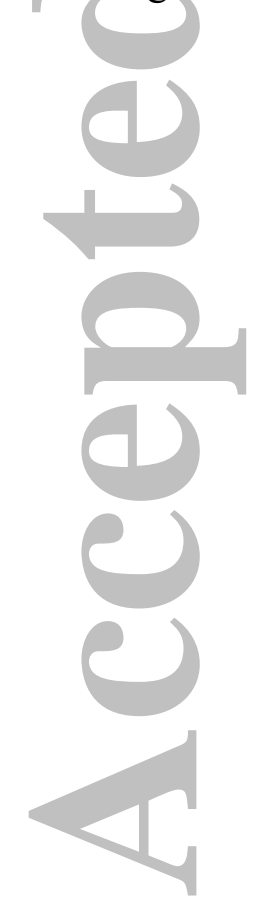


TABLES

\begin{tabular}{|c|c|c|c|c|c|c|c|c|}
\hline \multicolumn{9}{|c|}{$\mathbf{M}(\mathbf{t})=\mathbf{V}(\mathbf{t})^{\mathbf{b}}$} \\
\hline & \multicolumn{2}{|l|}{ July 1} & \multicolumn{2}{|c|}{ August 11} & \multicolumn{2}{|c|}{ August 19} & \multicolumn{2}{|c|}{ September 10} \\
\hline & b-value & $\mathrm{R}^{2}$ & b-value & $\mathrm{R}^{2}$ & b-value & $\mathrm{R}^{2}$ & b-value & $\mathrm{R}^{2}$ \\
\hline $\mathrm{TP}(\mathrm{mg} / \mathrm{L})$ & 0.775 & 0.748 & 0.723 & 0.839 & 0.799 & 0.795 & 0.908 & 0.866 \\
\hline $\mathrm{TSS}(\mathrm{mg} / \mathrm{L})$ & $\mathrm{N} / \mathrm{A}$ & N/A & 0.684 & 0.850 & 0.708 & 0.687 & 0.893 & 0.788 \\
\hline
\end{tabular}

586

587 Table 1: The coefficients of determination and b-values for power law functions for total phosphorus (TP) and TSS.

588

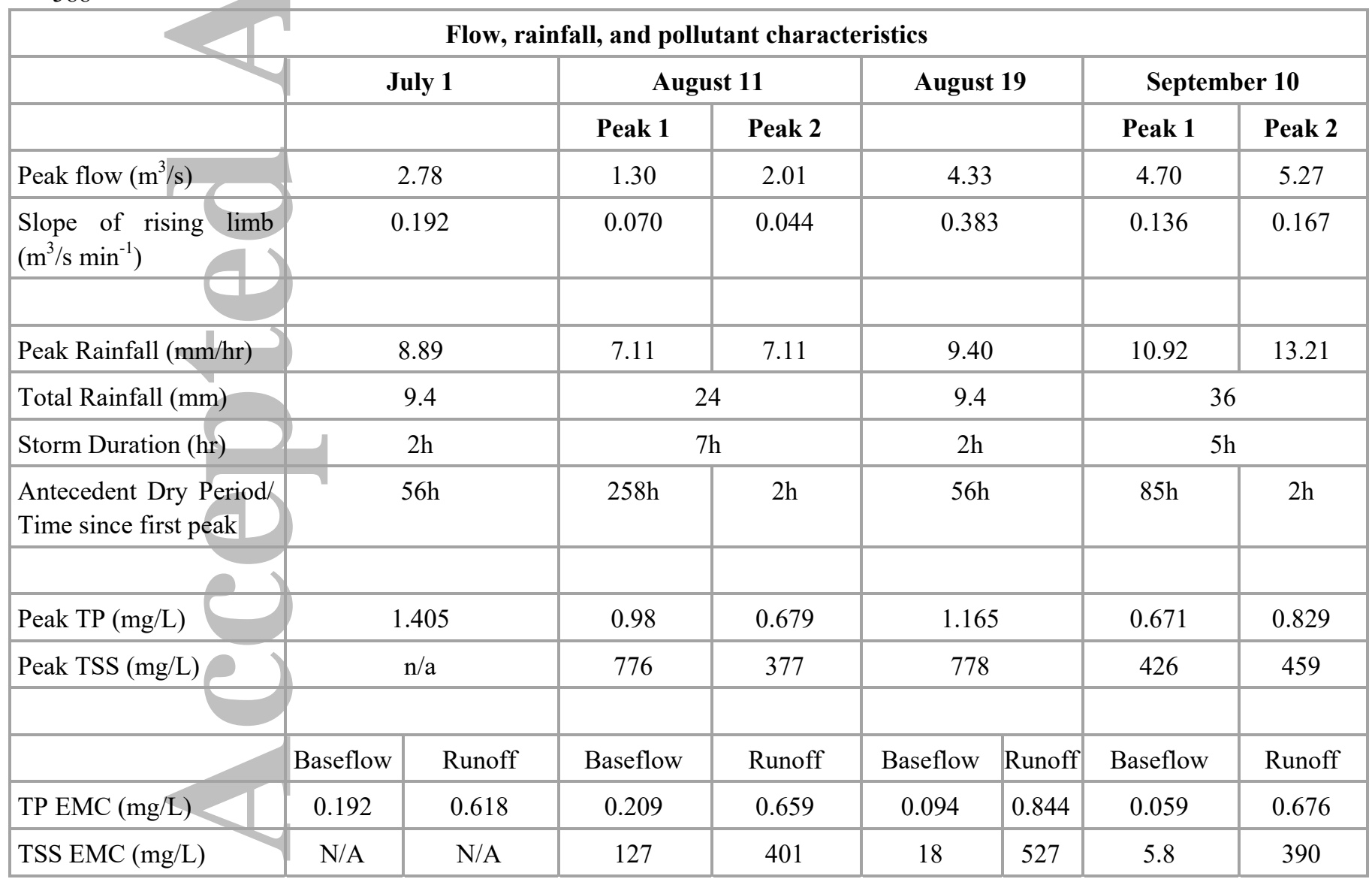

589

590

591
Table 2: The characteristics for each measured storm event, including peak flow information, rainfall, and the event mean concentrations (EMCs) for total phosphorus (TP) and TSS. 

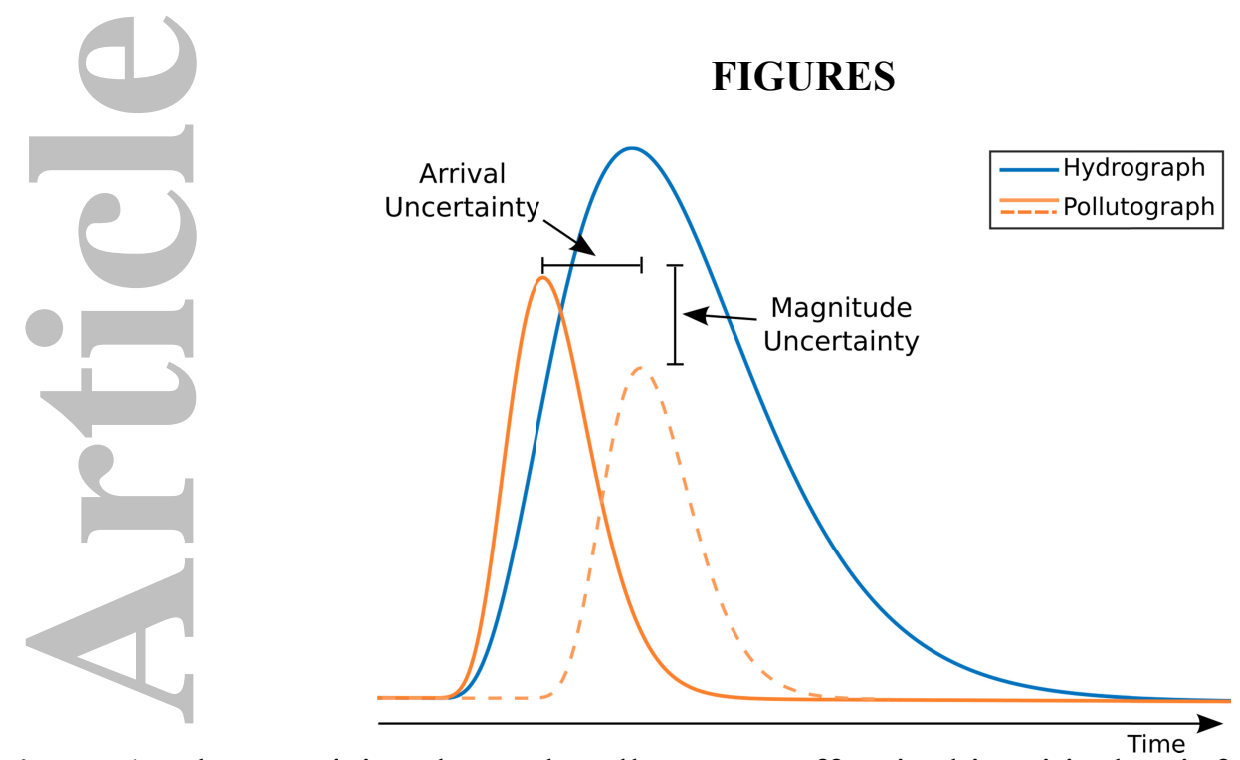

Figure 1: Characterizing the peak pollutant runoff arrival is critical to informing impacts of land use and water quality control practices, which often rely on assumptions of a first flush.
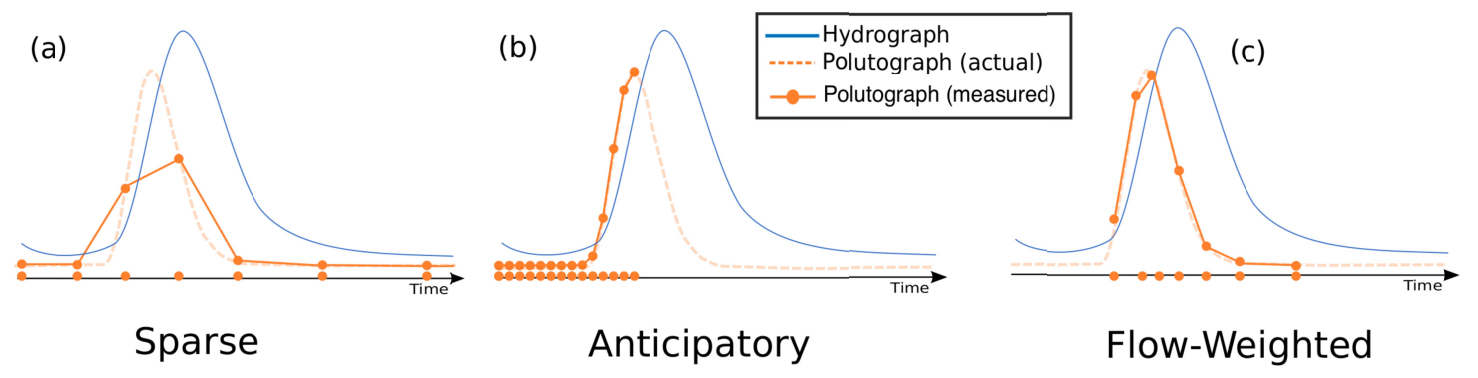

Figure 2: (a) Undersampling reduces the use of constrained experimental resources but can lead to an improperly reconstructed water quality signal, (b) rapid sampling may deplete all of the sampling resources before the event is complete, (c) triggering on flow thresholds or storm intensities alone may miss the onset of smaller events. 


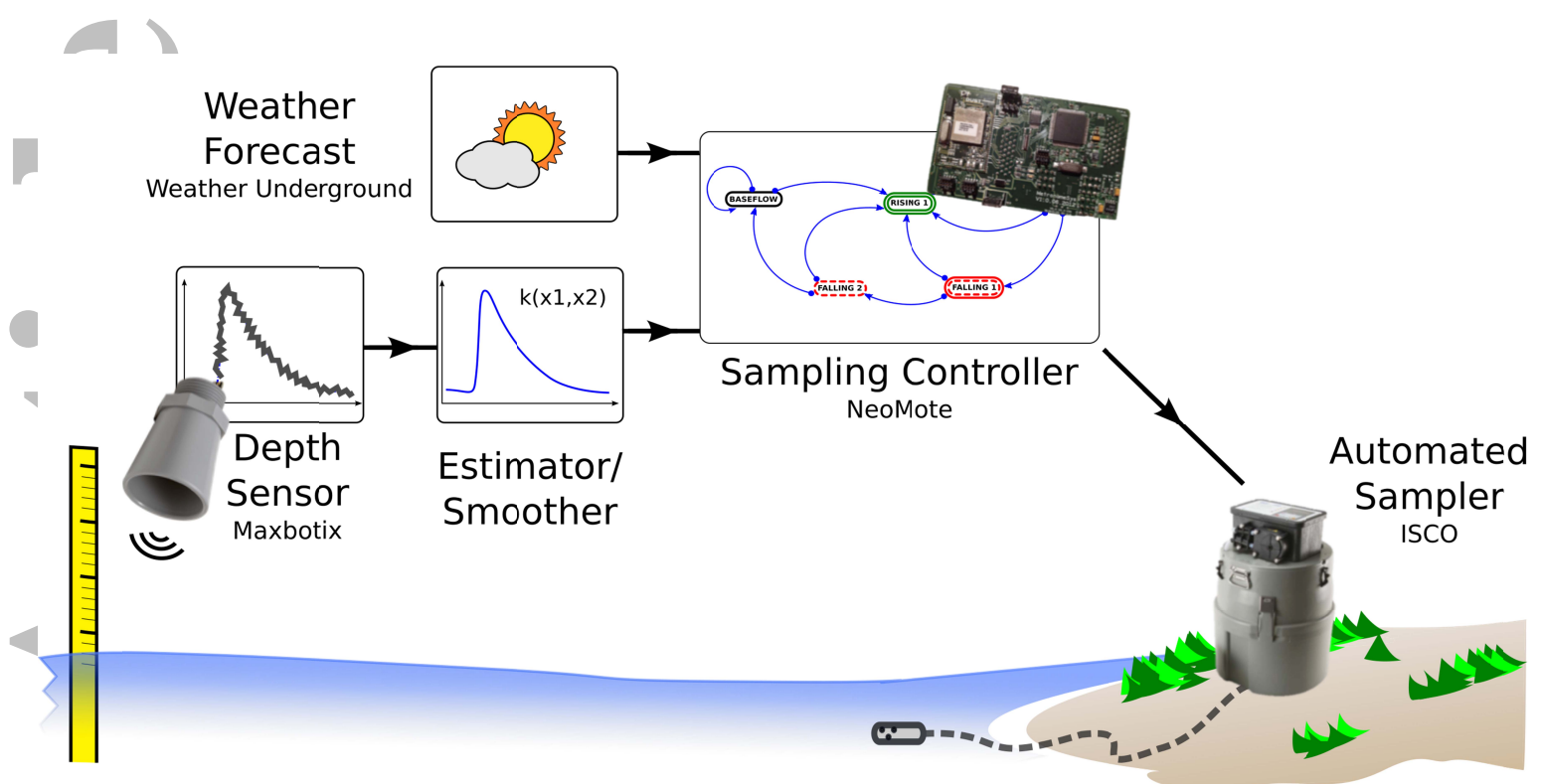

Figure 3: Forecast data is acquired in real-time from the Internet and fused with filtered, realtime sensor data to trigger the automated sampler based on relevant hydrologic states.

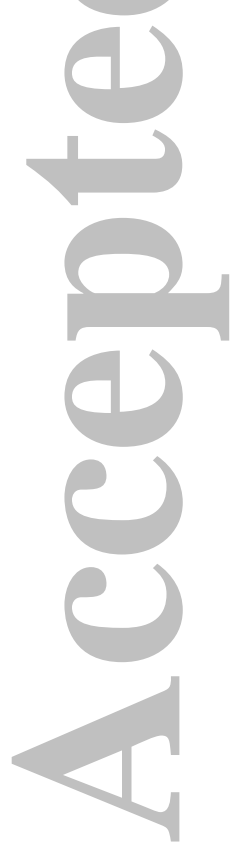




$\begin{array}{ll}\text { Algorithm } 1 \\ 0: & \text { Inputs: Rain Forecast }(R), \text { Flow or Stage }(x) \\ 1: & \text { Initialize the current state } s \text { to "Baseflow" } \\ 2: & \text { while TRUE do } \\ 3: & \text { Update the state } s \text { and sample time } t_{s} \text { based on }(\dot{x}, \ddot{x}) \\ 4: & \text { if s changed } \\ 5: & \text { Trigger Sample } \\ 6: & \text { Wait } t_{s} \text { before next update }\end{array}$

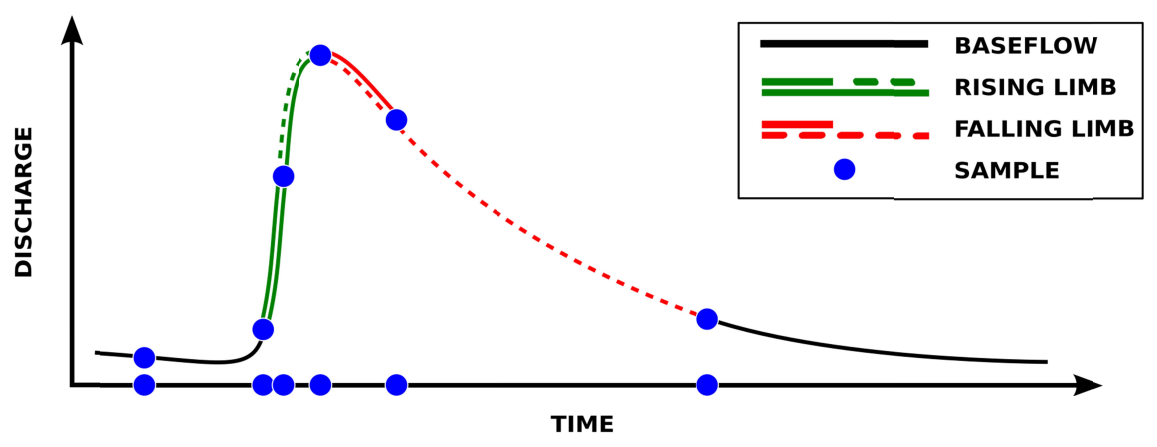

Figure 4: Adaptive sampling algorithm (above) and corresponding state machine (below). 


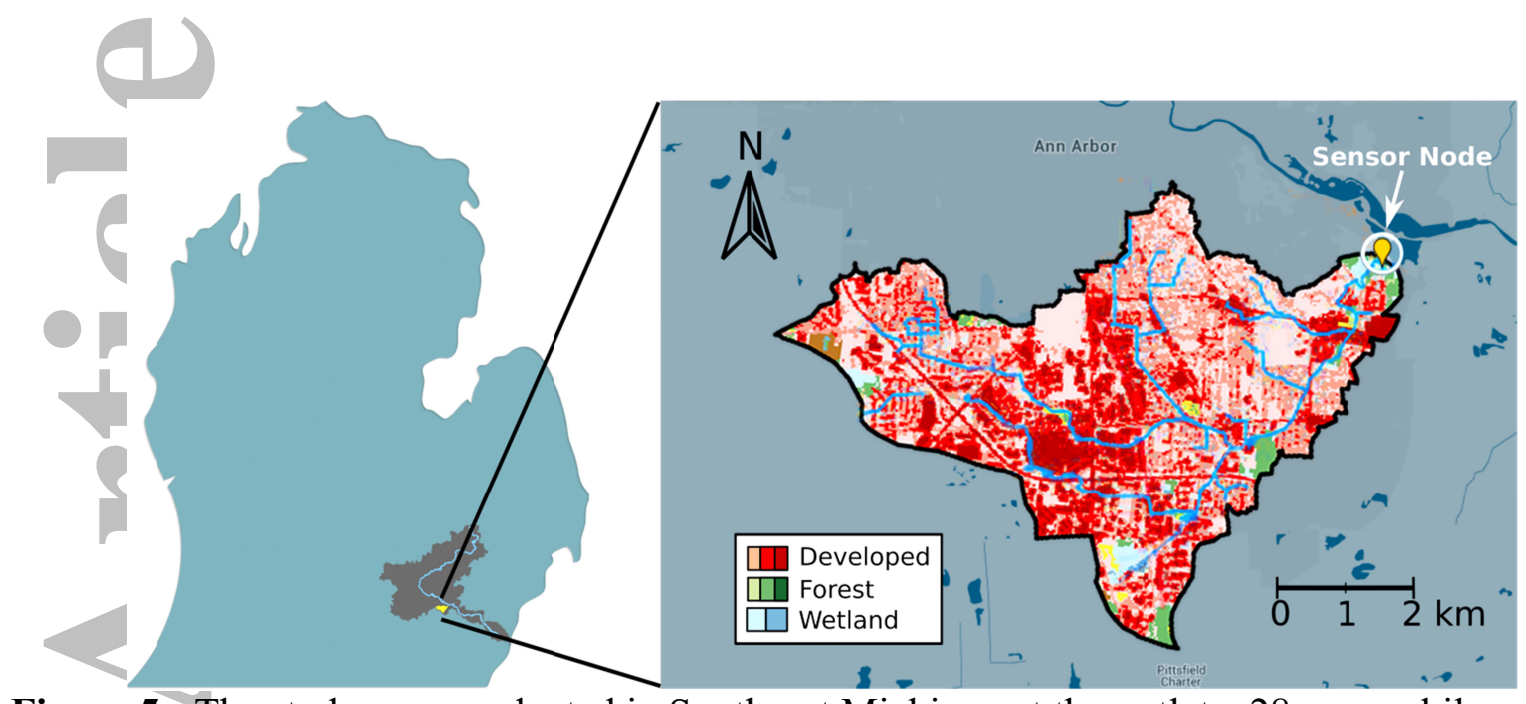

Figure 5: The study was conducted in Southeast Michigan at the outlet a 28 square kilometer urban watershed.

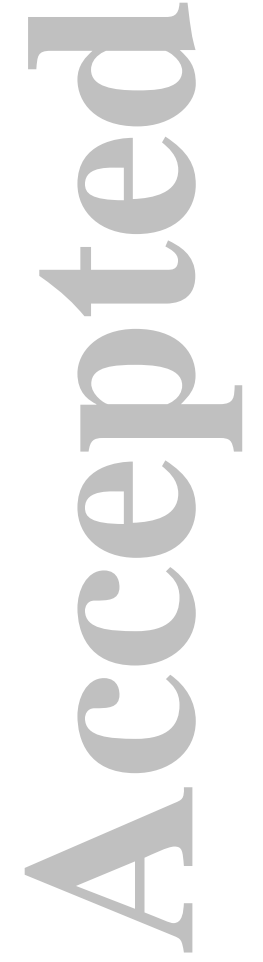




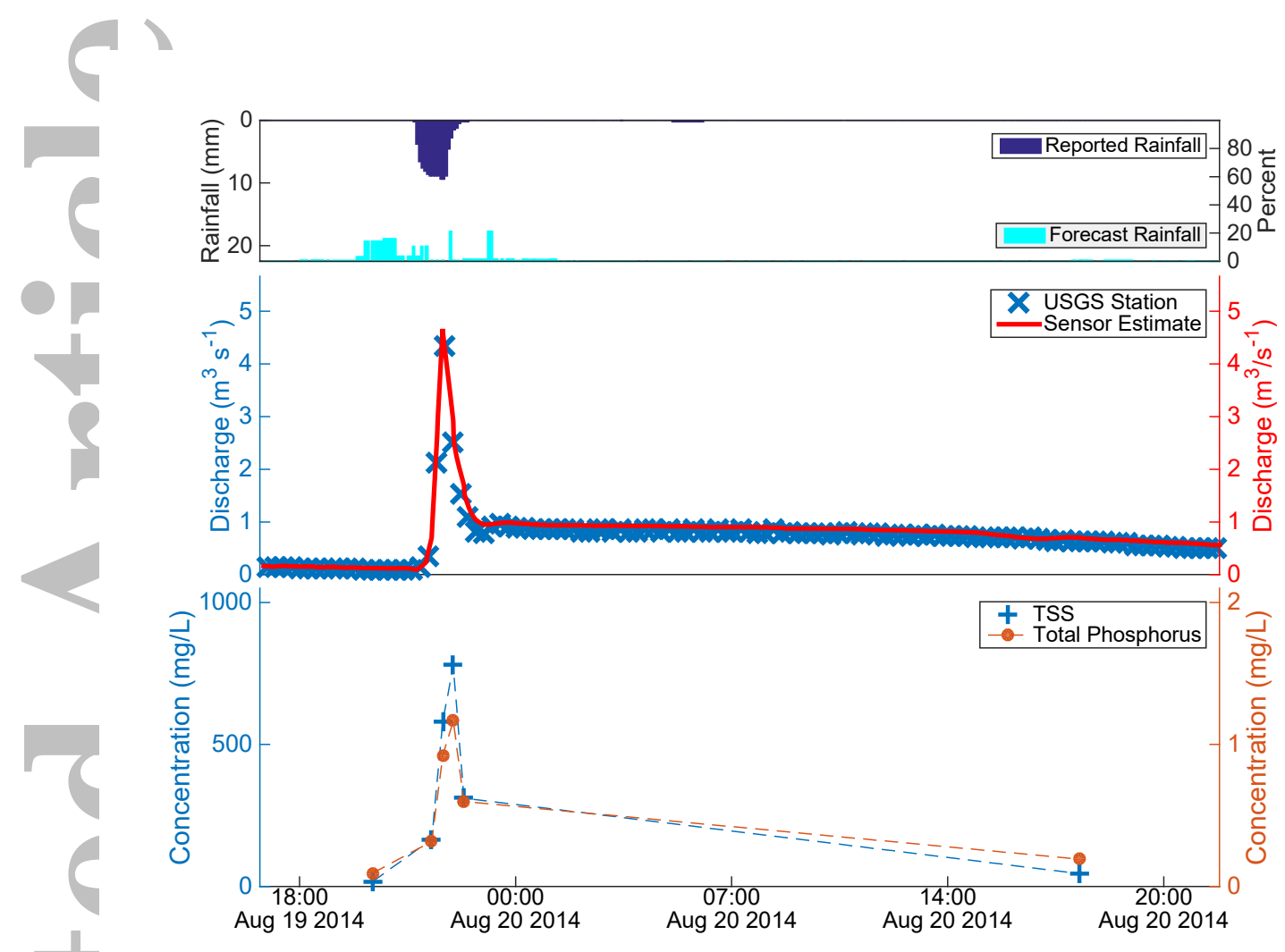

Figure 6: Forecasted rainfall and measured hyetograph from Weather Underground (top). Hydrograph reported by nearby USGS gage and estimated by local depth sensor (middle). Linearly interpolated pollutograph for total suspended solids (TSS) and total phosphorus (bottom). Markers indicate samples triggered by the algorithm. 

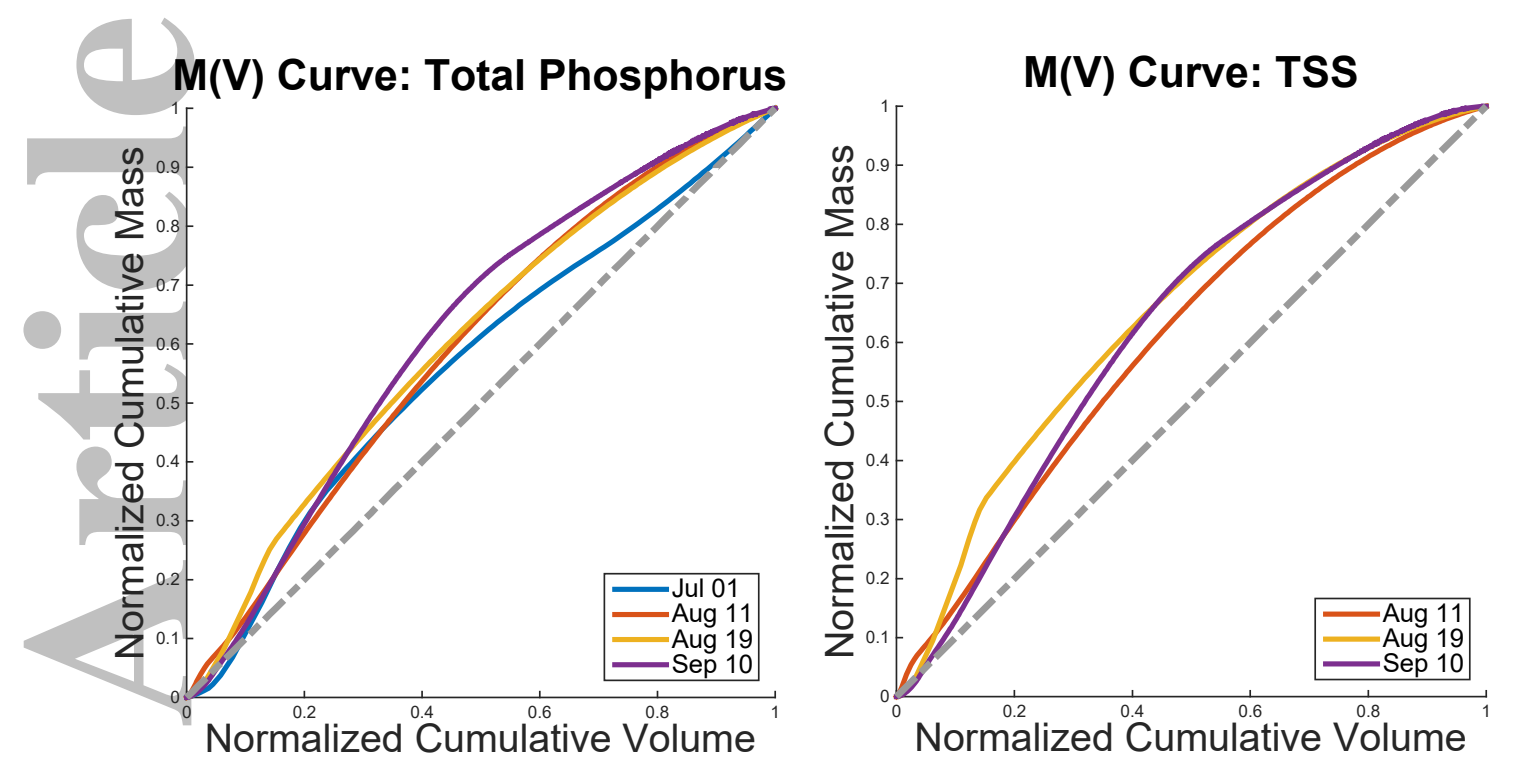

Figure 7: Cumulative mass volume curves for total phosphorus (left) and total suspended solids (right). Dashed line indicates uniform pollutant concentration.

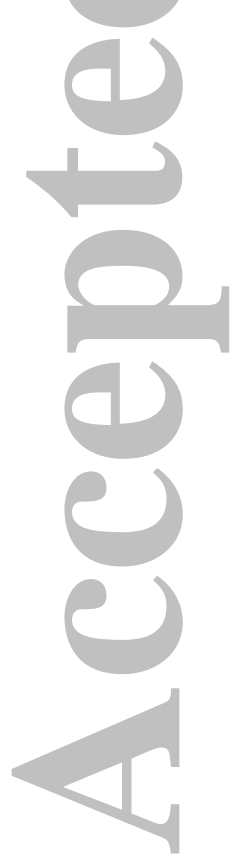




\section{REFERENCES}

Akyildiz IF, Su W, Sankarasubramaniam Y, Cayirci E. 2002. Wireless sensor networks: A survey. Computer Networks 38(4):393-422.

Amazon Web Services (AWS) - Cloud Computing Services [Internet]; c2016 [cited 2016 10/01]. Available from: https://aws.amazon.com/.

Anderson CW and Rounds S. 2010. Use of continuous monitors and autosamplers to predict unmeasured water-quality constituents in tributaries of the tualatin river, oregon. US Department of the Interior, US Geological Survey.

Bach PM, McCarthy DT, Deletic A. 2010. Redefining the stormwater first flush phenomenon. Water Res 44(8):2487-98.

Baker DB, Richards RP, Loftus TT, Kramer JW. 2004. A new flashiness index: Characteristics and applications to midwestern rivers and streams. J Am Water Resour Assoc 40(2):503-22.

Barbosa A, Fernandes J, David L. 2012. Key issues for sustainable urban stormwater management. Water Res 46(20):6787-98.

Barrett ME. 2005. Performance comparison of structural stormwater best management practices. Water Environ Res 77(1):78-86.

Beck HJ and Birch GF. 2012. Metals, nutrients and total suspended solids discharged during different flow conditions in highly urbanised catchments. Environ Monit Assess 184(2):637-53.

Benedict MA and McMahon ET. 2006. Green infrastructure. Island, Washington, DC .

Bertrand-Krajewski J, Chebbo G, Saget A. 1998. Distribution of pollutant mass vs volume in stormwater discharges and the first flush phenomenon. Water Res 32(8):2341-56.

Booth DB and Jackson CR. 1997. Urbanization of aquatic systems: Degradation thresholds, stormwater detection, and the limits of mitigation. J Am Water Resour Assoc 33(5):1077-90.

Characklis GW and Wiesner MR. 1997. Particles, metals, and water quality in runoff from large urban watershed. J Environ Eng 123(8):753-9.

Corke P, Wark T, Jurdak R, Hu W, Valencia P, Moore D. 2010. Environmental wireless sensor networks. Proc IEEE 98(11):1903-17. 
CUASHI [Internet]; c2016 [cited 2016 01/12]. Available from: https://www.cuahsi.org/wdc .

Deletic A. 1998. The first flush load of urban surface runoff. Water Res 32(8):2462-70.

Dolan DM and McGunagle KP. 2005. Lake erie total phosphorus loading analysis and update: 19962002. J Great Lakes Res 31:11-22.

Edwards WJ, Conroy JD, Culver DA. 2005. Hypolimnetic oxygen depletion dynamics in the central basin of lake erie. J Great Lakes Res 31:262-71.

Eleria A and Vogel RM. 2005. Predicting Fecal Coliform Bacteria Levels in the Charles River, Massachusetts, Usa1 .

Ellison ME and Brett MT. 2006. Particulate phosphorus bioavailability as a function of stream flow and land cover. Water Res 40(6):1258-68.

Fletcher TD and Deletic A. 2007. Statistical observations of a stormwater monitoring programme: Lessons for the estimation of pollutant loads. NOVATECH 2007.

Gall HE, Jafvert CT, Jenkinson B. 2010. Integrating hydrograph modeling with real-time flow monitoring to generate hydrograph-specific sampling schemes. Journal of Hydrology 393(3):331.

Gnecco I, Berretta C, Lanza L, La Barbera P. 2005. Storm water pollution in the urban environment of genoa, italy. Atmos Res 77(1):60-73.

Grayson R, Finlayson BL, Gippel C, Hart B. 1996. The potential of field turbidity measurements for the computation of total phosphorus and suspended solids loads. J Environ Manage 47(3):257-67.

Harmel R, Slade R, Haney R. 2010. Impact of sampling techniques on measured stormwater quality data for small streams. J Environ Qual 39(5):1734-42.

Harmel R, King K, Slade R. 2003. Automated storm water sampling on small watersheds. Appl Eng Agric 19(6):667-74.

Harmel R, Cooper R, Slade R, Haney R, Arnold J. 2006. Cumulative uncertainty in measured streamflow and water quality data for small watersheds. Transactions-American Society of Agricultural Engineers 49(3):689.

Hart JK and Martinez K. 2006. Environmental sensor networks: A revolution in the earth system science? Earth-Sci Rev 78(3):177-91. 
Hastie T, Tibshirani R, Friedman J. 2009. The elements of statistical learning. .

Hathaway JM and Hunt WF. 2011. Evaluation of first flush for indicator bacteria and total suspended solids in urban stormwater runoff. Water, Air, \& Soil Pollution 217(1-4):135-47.

Hawley R and Vietz G. 2016. Addressing the urban stream disturbance regime. Freshwater Science :000-.

Hensley RT, Cohen MJ, Korhnak LV. 2015. Hydraulic effects on nitrogen removal in a tidal spring-fed river. Water Resour Res 51(3):1443-56.

Hill D, Kerkez B, Rasekh A, Ostfeld A, Minsker B, Banks MK. 2014. Sensing and cyberinfrastructure for smarter water management: The promise and challenge of ubiquity. J Water Resour Plann Manage 140(7):01814002.

Horowitz AJ. 2009. Monitoring suspended sediments and associated chemical constituents in urban environments: Lessons from the city of atlanta, georgia, USA water quality monitoring program. Journal of Soils and Sediments 9(4):342-63.

Horsburgh JS, Jones AS, Stevens DK, Tarboton DG, Mesner NO. 2010. A sensor network for high frequency estimation of water quality constituent fluxes using surrogates. Environmental Modelling \& Software 25(9):1031-44.

InfluxDB - Time-Series Data Storage | InfluxData [Internet]; c2016 [cited 2016 10/01]. Available from: https://www.influxdata.com/time-series-platform/influxdb/ .

Kerkez B, Gruden C, Lewis MJ, Montestruque L, Quigley M, Wong BP, Bedig A, Kertesz R, Braun T, Cadwalader O. 2016. Smarter stormwater systems. Environ Sci Technol .

Krause A., Rajagopal R., Gupta A. and Guestrin C. 2009. Simultaneous placement and scheduling of sensors. $.181 \mathrm{p}$.

Langeveld J, Liefting H, Boogaard F. 2012. Uncertainties of stormwater characteristics and removal rates of stormwater treatment facilities: Implications for stormwater handling. Water Res 46(20):6868-80.

Lee JH and Bang KW. 2000. Characterization of urban stormwater runoff. Water Res 34(6):1773-80.

Leecaster MK, Schiff K, Tiefenthaler LL. 2002. Assessment of efficient sampling designs for urban stormwater monitoring. Water Res 36(6):1556-64. 
Li L, Yin C, He Q, Kong L. 2007. First flush of storm runoff pollution from an urban catchment in china. Journal of Environmental Sciences 19(3):295-9.

McCarthy D, Hathaway J, Hunt W, Deletic A. 2012. Intra-event variability of escherichia coli and total suspended solids in urban stormwater runoff. Water Res 46(20):6661-70.

Métadier M and Bertrand-Krajewski J. 2012. The use of long-term on-line turbidity measurements for the calculation of urban stormwater pollutant concentrations, loads, pollutographs and intra-event fluxes. Water Res 46(20):6836-56.

Miller MP, Tesoriero AJ, Capel PD, Pellerin BA, Hyer KE, Burns DA. 2015. Quantifying watershedscale groundwater loading and in-stream fate of nitrate using high-frequency water quality data. Water Resour Res .

Montestruque Luis and Lemmon MD. 2015. Globally coordinated distributed storm water management system. Proceedings of the 1st ACM international workshop on cyber-physical systems for smart water networksACM. 10 p.

Montgomery JL, Harmon T, Haas CN, Hooper R, Clesceri NL, Graham W, Kaiser W, Sanderson A, Minsker B, Schnoor J. 2007. The waters network: An integrated environmental observatory network for water research. Environ Sci Technol 41(19):6642-7.

Ocampo-Martinez C, Puig V, Cembrano G, Quevedo J. 2013. Application of predictive control strategies to the management of complex networks in the urban water cycle [applications of control]. IEEE Control Systems 33(1):15-41.

Oliveira LM and Rodrigues JJ. 2011. Wireless sensor networks: A survey on environmental monitoring. Journal of Communications 6(2):143-51.

Padowski JC and Jawitz JW. 2012. Water availability and vulnerability of 225 large cities in the united states. Water Resour Res 48(12).

Paul MJ and Meyer JL. 2001. Streams in the urban landscape. Annu Rev Ecol Syst :333-65.

Pellerin BA, Downing BD, Kendall C, Dahlgren RA, Kraus TE, Saraceno J, Spencer RG, Bergamaschi BA. 2009. Assessing the sources and magnitude of diurnal nitrate variability in the san joaquin river (california) with an in situ optical nitrate sensor and dual nitrate isotopes. Freshwat Biol 54(2):37687. 
Quigley M and Brown C. 2015. Transforming our cities: High-performance green infrastructure. Water Intelligence Online 14:9781780406732.

Rawat P, Singh KD, Chaouchi H, Bonnin JM. 2014. Wireless sensor networks: A survey on recent developments and potential synergies. The Journal of Supercomputing 68(1):1-48.

Rees P, Long S, Baker R, Bordeau D, Pei R. 2006. Development of event-based pathogen monitoring strategies for watersheds. American Water Works Association.

Reeves J, Chen J, Wang XL, Lund R, Lu QQ. 2007. A review and comparison of changepoint detection techniques for climate data. Journal of Applied Meteorology and Climatology 46(6):900 $<$ last_page $>915$.

Rowny JG and Stewart JR. 2012. Characterization of nonpoint source microbial contamination in an urbanizing watershed serving as a municipal water supply. Water Res 46(18):6143-53.

Roy-Poirier A, Champagne P, Filion Y. 2010. Review of bioretention system research and design: Past, present, and future. J Environ Eng 136(9):878-89.

Rucinski DK, Beletsky D, DePinto JV, Schwab DJ, Scavia D. 2010. A simple 1-dimensional, climate based dissolved oxygen model for the central basin of lake erie. J Great Lakes Res 36(3):465-76.

Rügner H, Schwientek M, Beckingham B, Kuch B, Grathwohl P. 2013. Turbidity as a proxy for total suspended solids (TSS) and particle facilitated pollutant transport in catchments. Environmental Earth Sciences 69(2):373-80.

Sansalone JJ and Cristina CM. 2004. First flush concepts for suspended and dissolved solids in small impervious watersheds. J Environ Eng 130(11):1301<last_page> 1314.

Singh Aarti, Nowak Robert and Ramanathan Parmesh. 2006. Active learning for adaptive mobile sensing networks. Proceedings of the 5th international conference on information processing in sensor networksACM. 60 p.

Tartakovsky A, Nikiforov I, Basseville M. 2014. Sequential analysis: Hypothesis testing and changepoint detection. CRC Press.

Teledyne Isco [Internet]; c2012 [cited 2016 May 31]. Available from: http://www.isco.com/WebProductFiles/Product_Literature/201/Stormwater_Monitoring_Guide.pdf . 
Tiefenthaler L, Schiff K, Leecaster M. 2000. Temporal variability patterns of stormwater concentrations in urban stormwater runoff. Southern California Coastal Water Research Project Annual Report :2844.

USEPA M. 1979. Methods for chemical analysis of water and wastes. Cincinnati, Ohio, USA .

Wagner RJ, Boulger Jr RW, Oblinger CJ, Smith BA. 2006. Guidelines and Standard Procedures for Continuous Water-Quality Monitors: Station Operation, Record Computation, and Data Reporting .

Walsh CJ, Roy AH, Feminella JW, Cottingham PD, Groffman PM, Morgan RP. 2005. The urban stream syndrome: Current knowledge and the search for a cure. J N Am Benthol Soc 24(3):706-23.

Weather Underground [Internet]; c2016 [cited 2016 01/12]. Available from: http://www.wunderground.com/.

Wise S. 2008. Green infrastructure rising. Planning 74(8):14-9.

Wong Brandon Preclaro and Kerkez Branko. GitHub Repository [Internet]; c2016 [cited 2016 01/12]. Available from: https://github.com/klabum/iot .

Wong Brandon Preclaro and Kerkez Branko. 2014a. A web service-based architecture for real-time hydrologic sensor networks. AGU 2014 fall meetingSan Francisco, CA. .

Wong Brandon Preclaro and Kerkez Branko. 2014b. Adaptive, decentralized, and real-time sampling strategies for resource constrained hydraulic and hydrologic sensor networks. HIC 2014 - 11th international conference on hydroinformaticsNew York, USA. .

Zhang Y, Meratnia N, Havinga P. 2010. Outlier detection techniques for wireless sensor networks: A survey. Communications Surveys \& Tutorials, IEEE 12(2):159-70. 
Figure 1. Figure
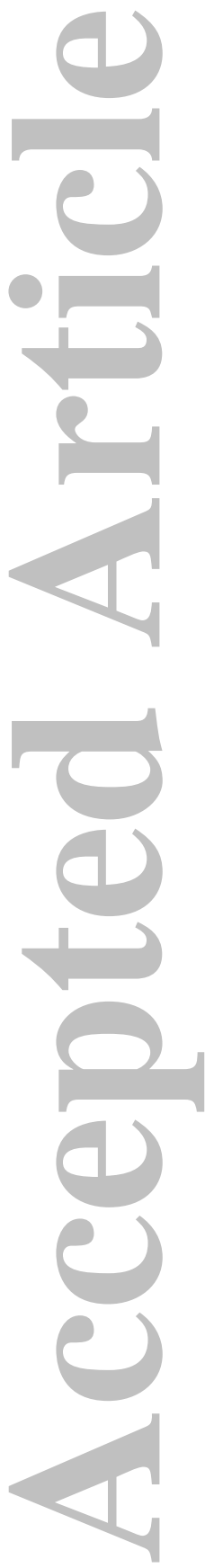

This article is protected by copyright. All rights reserved. 


\section{Arrival} Uncertainty
Hydrograph
Pollutograph

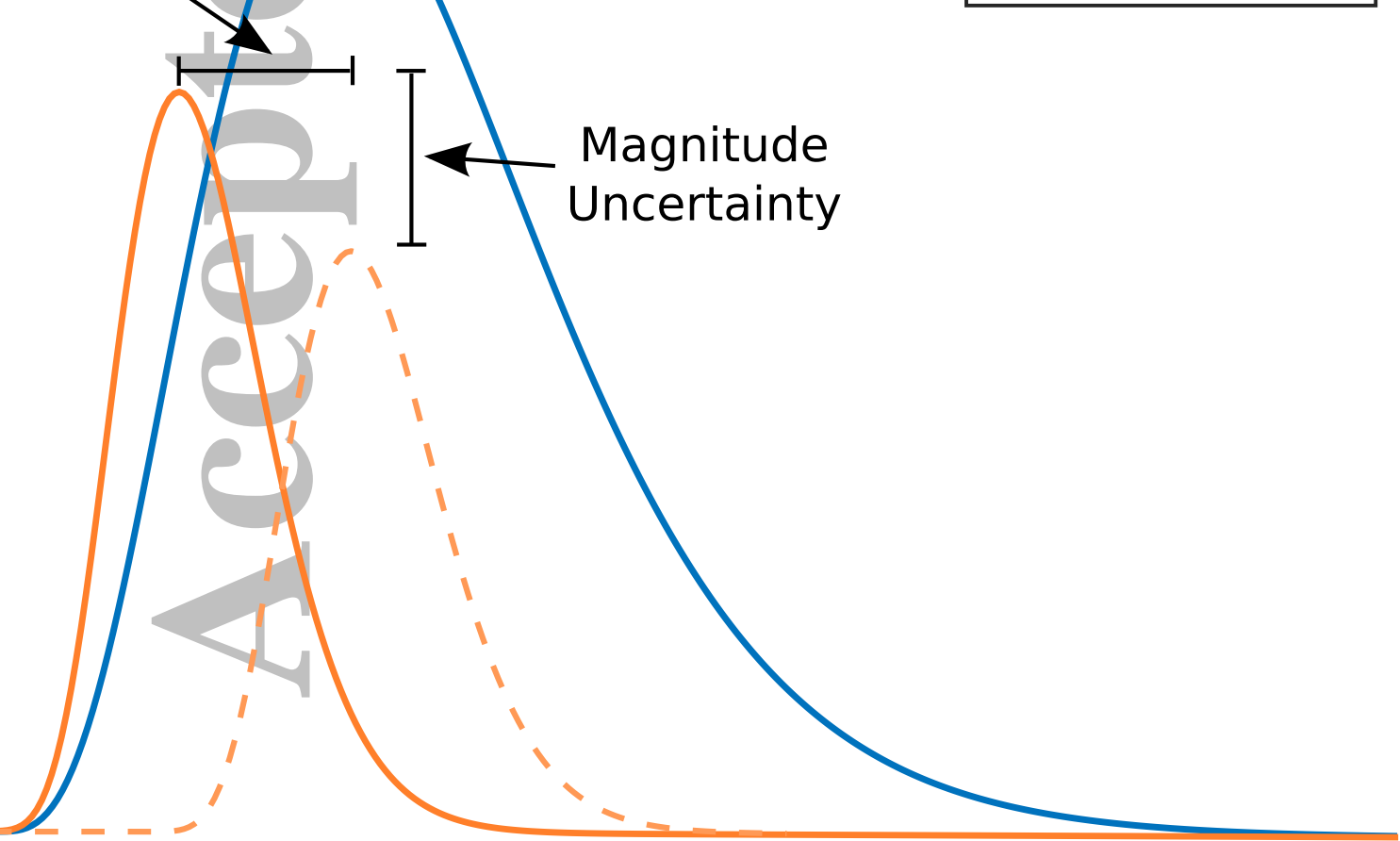

This articleis protected by oppyight. All ridats Time 
Figure 2.
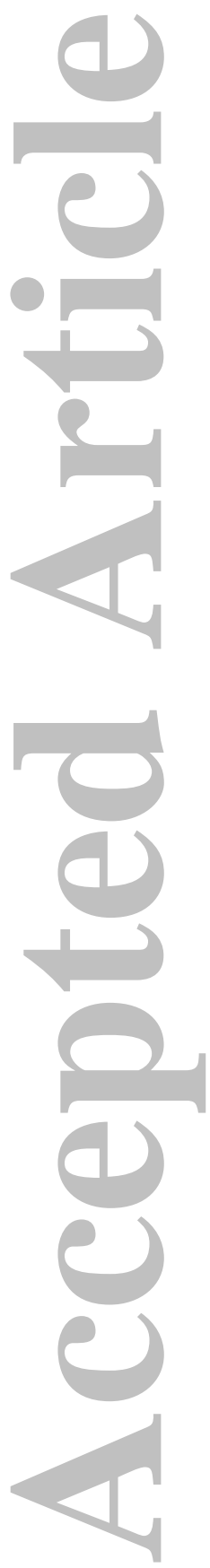

This article is protected by copyright. All rights reserved. 


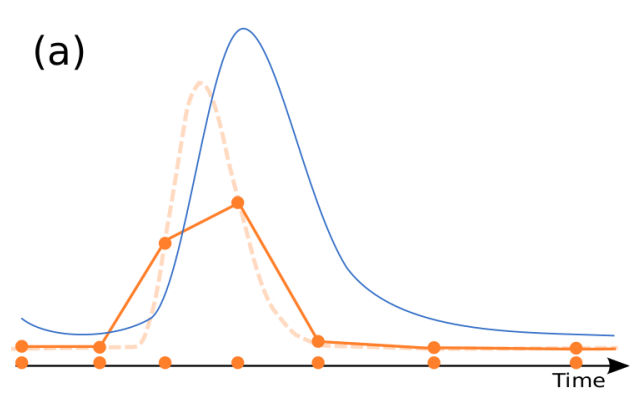

Sparse

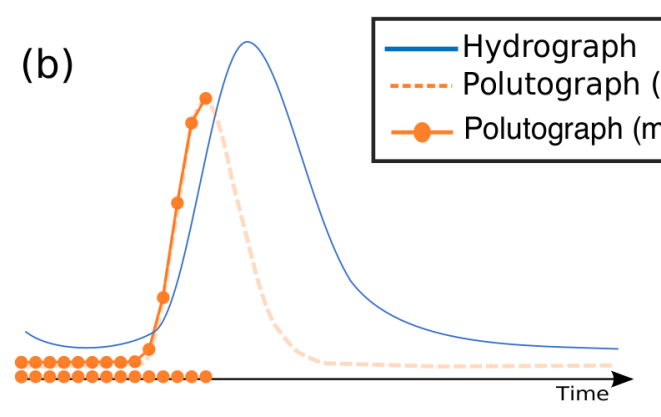

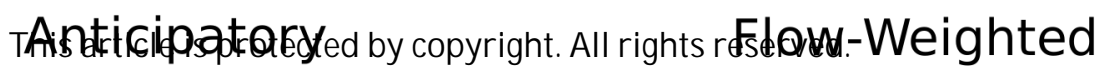


Figure 3. Figure
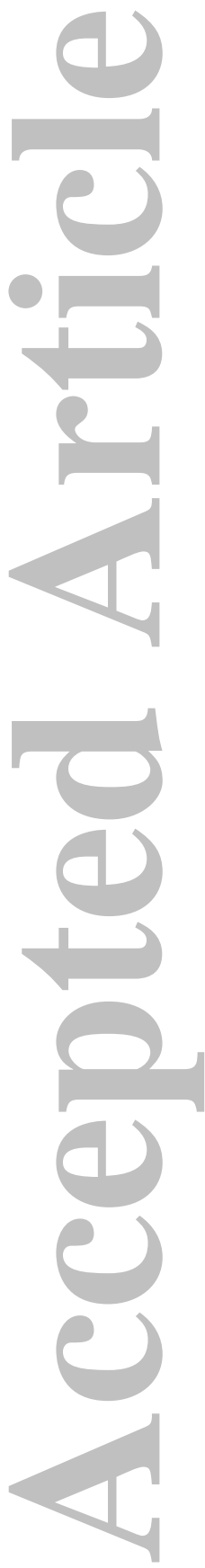

This article is protected by copyright. All rights reserved. 


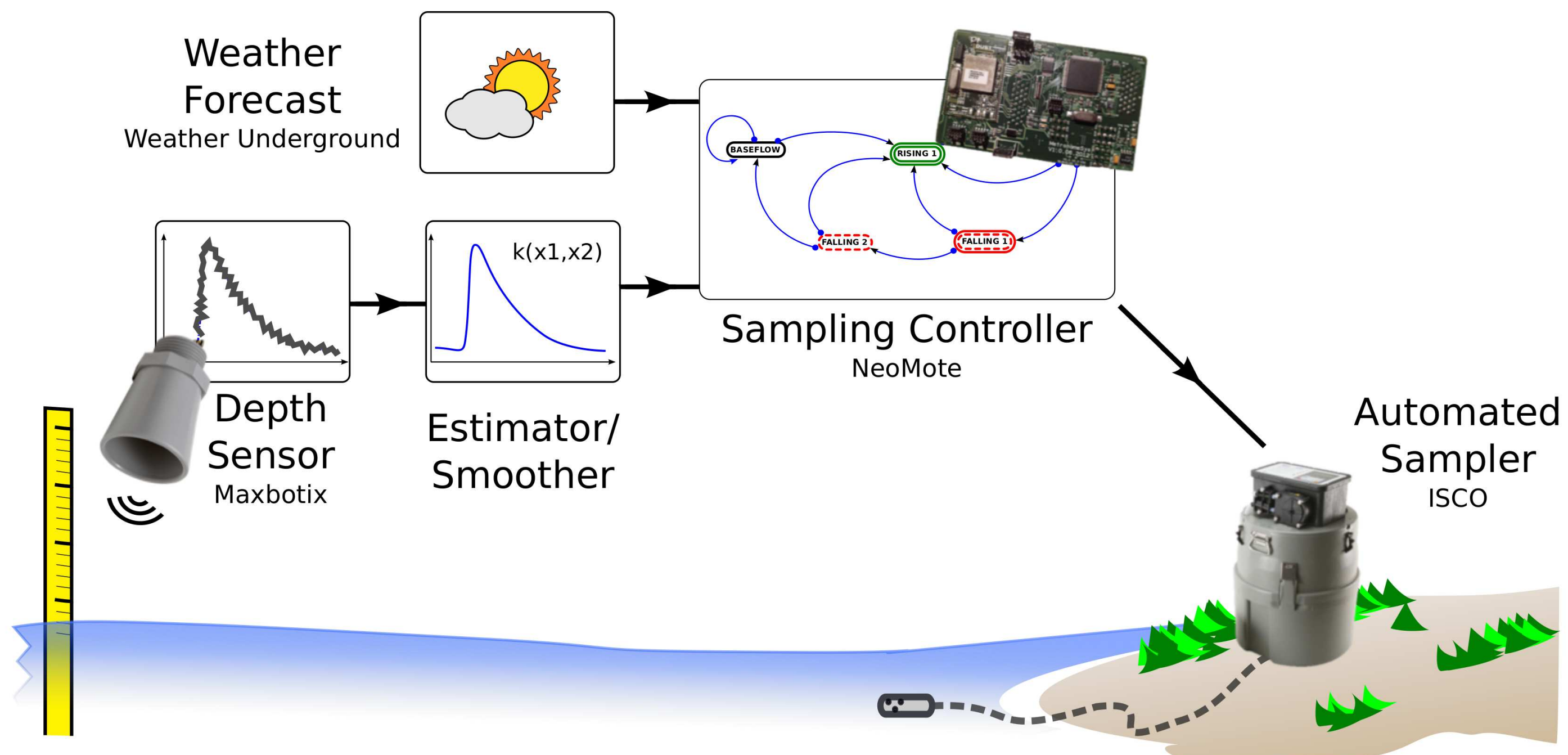


Figure 4. Figure
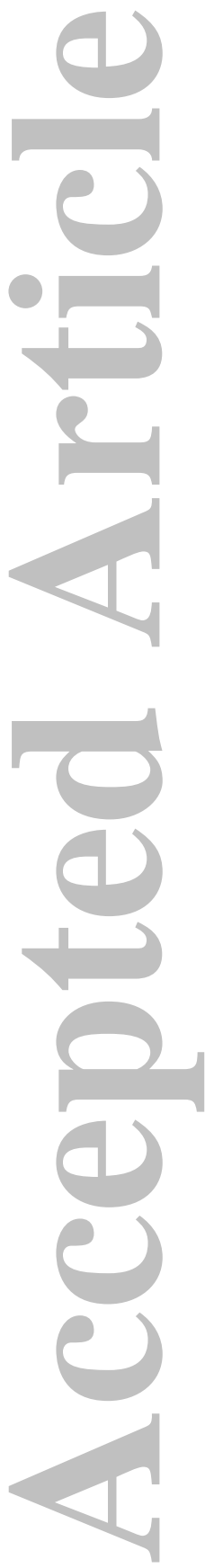

This article is protected by copyright. All rights reserved. 

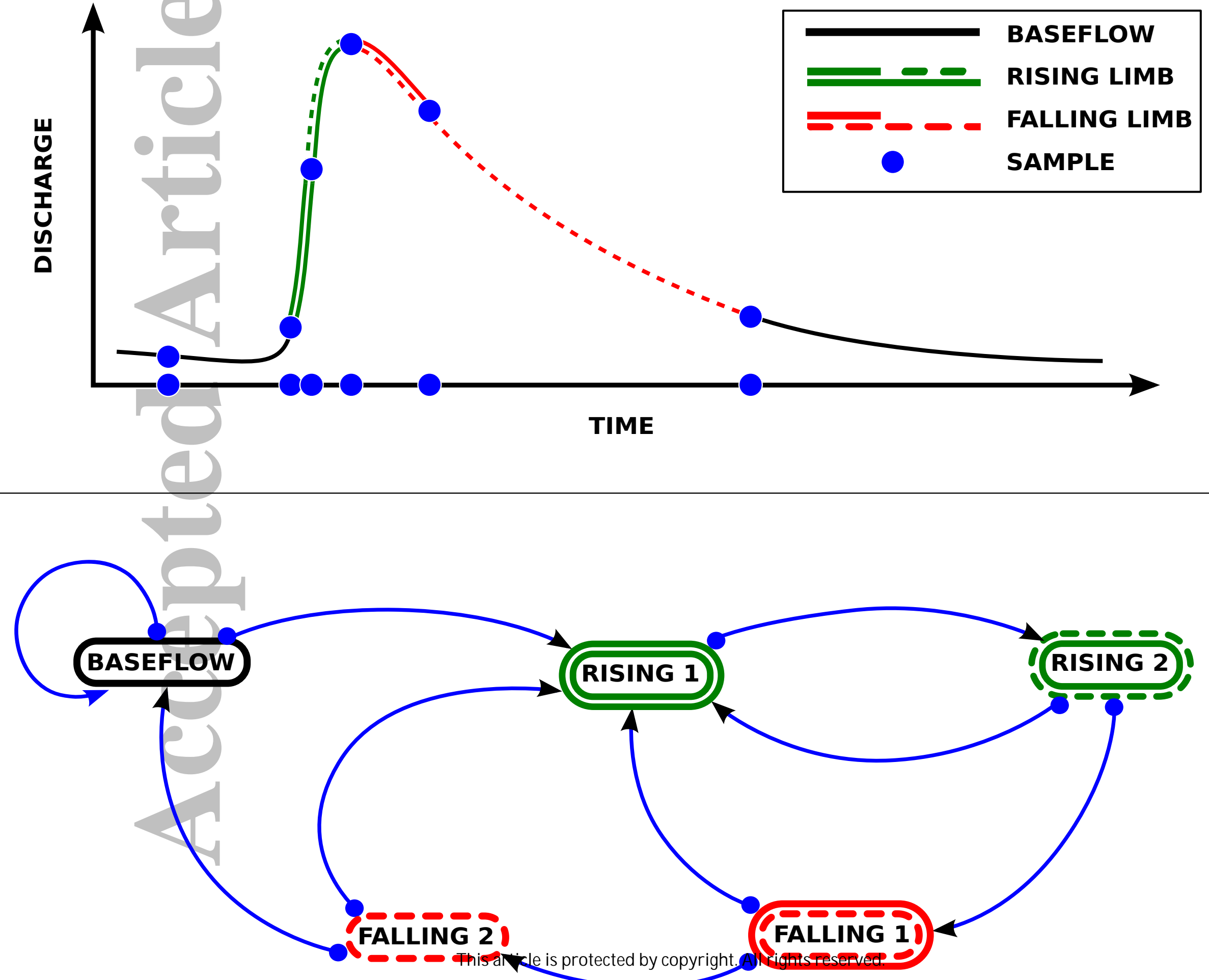
Figure 5. Figure
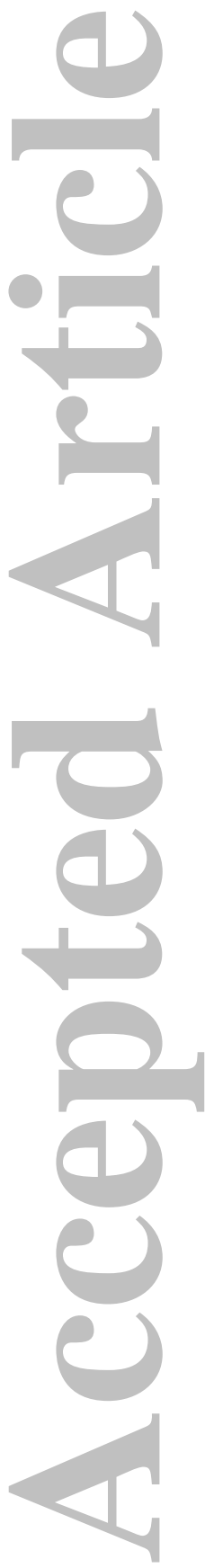

This article is protected by copyright. All rights reserved. 


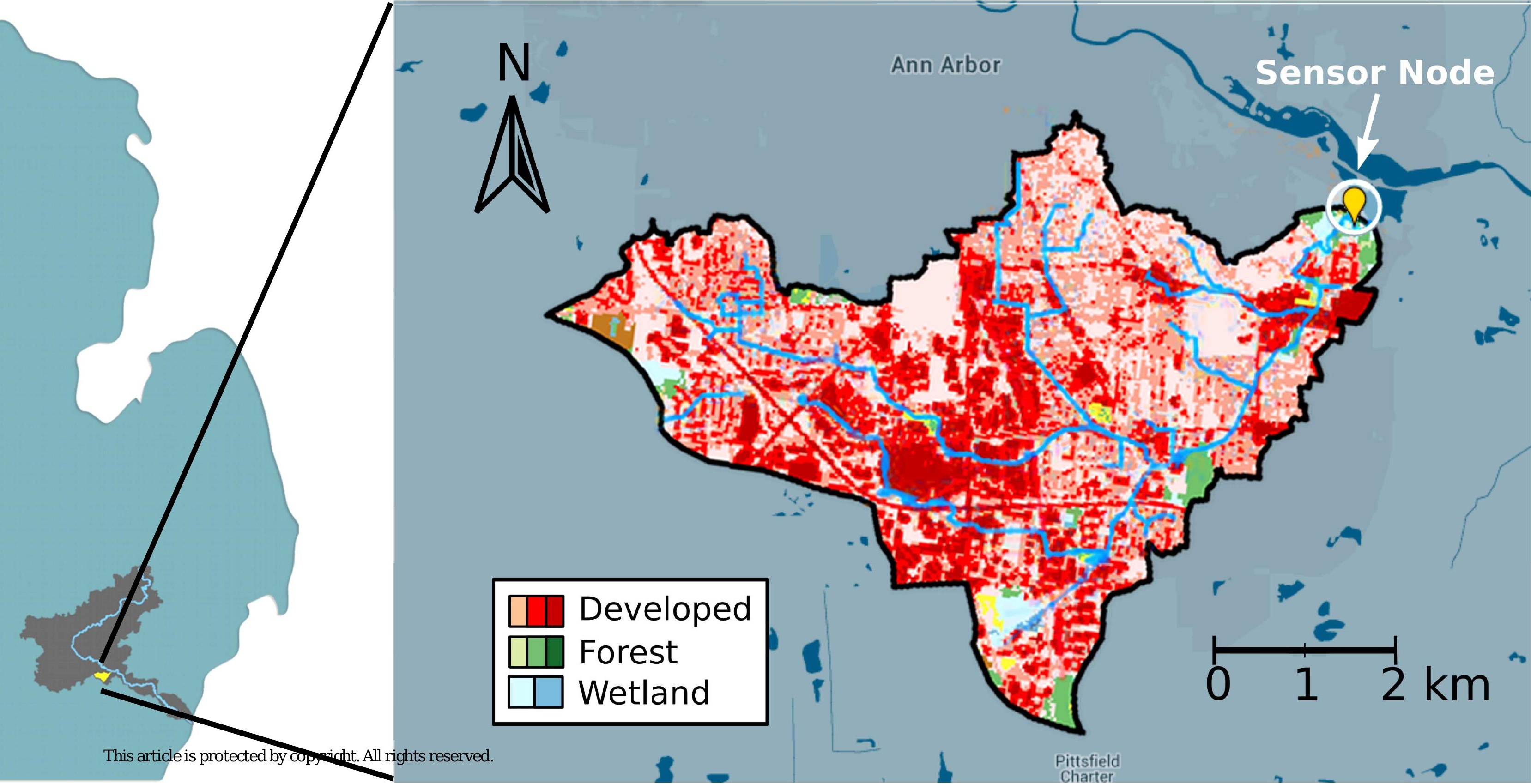


Figure 6.
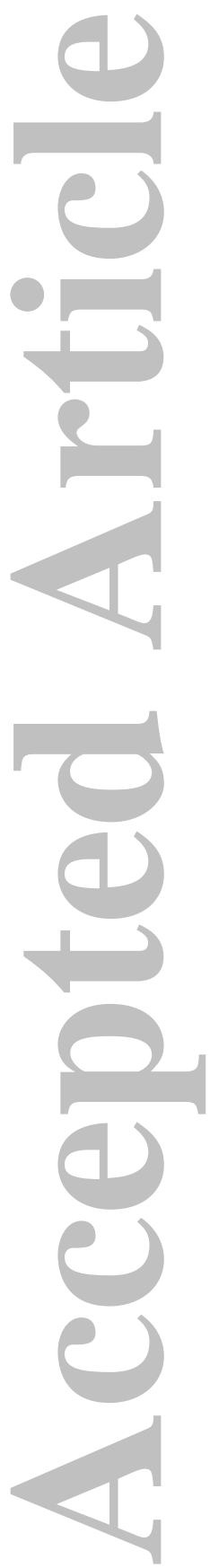

This article is protected by copyright. All rights reserved. 

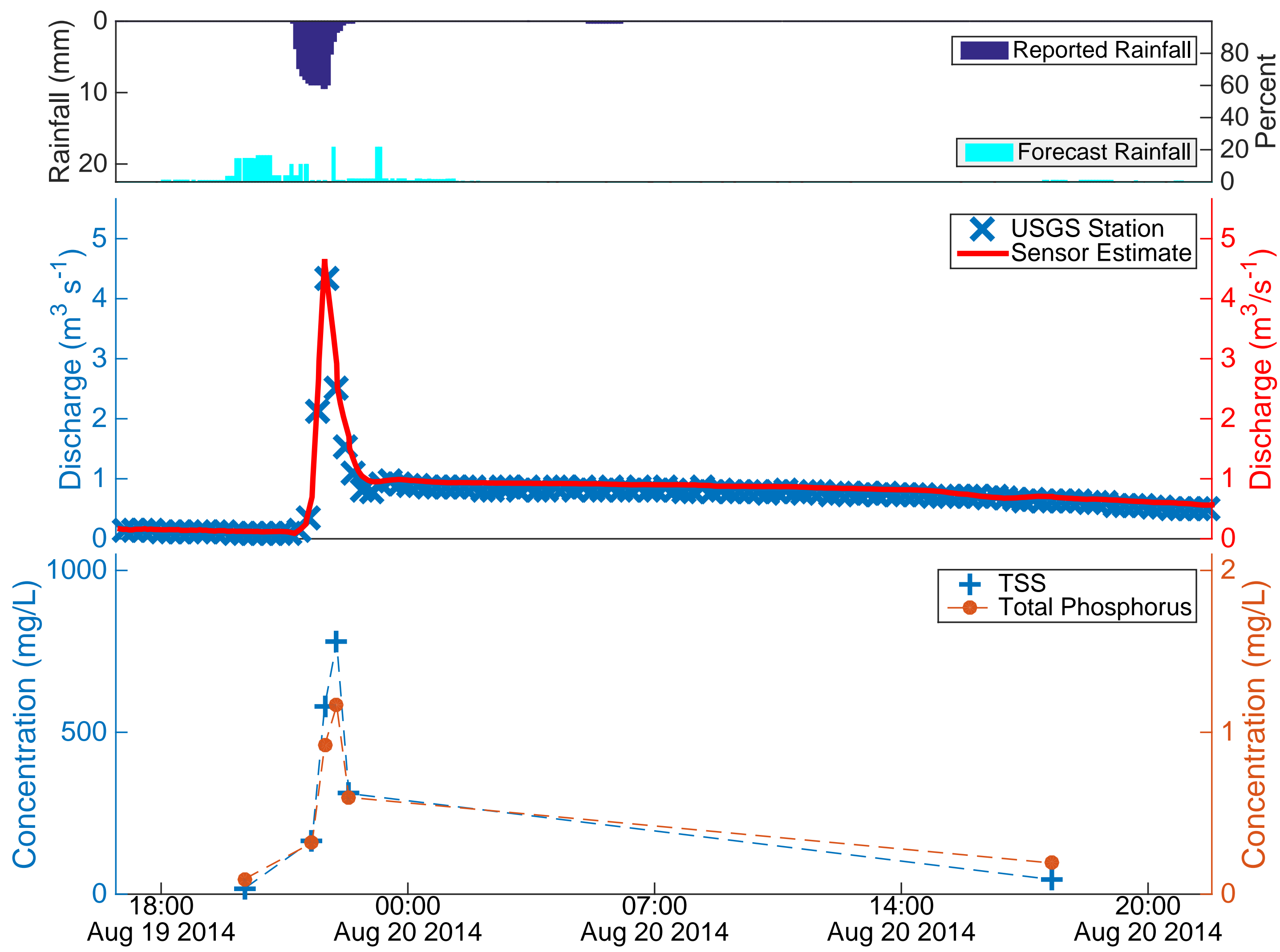

This article is protected by copyright. All rights reserved. 
Figure 7. Figure
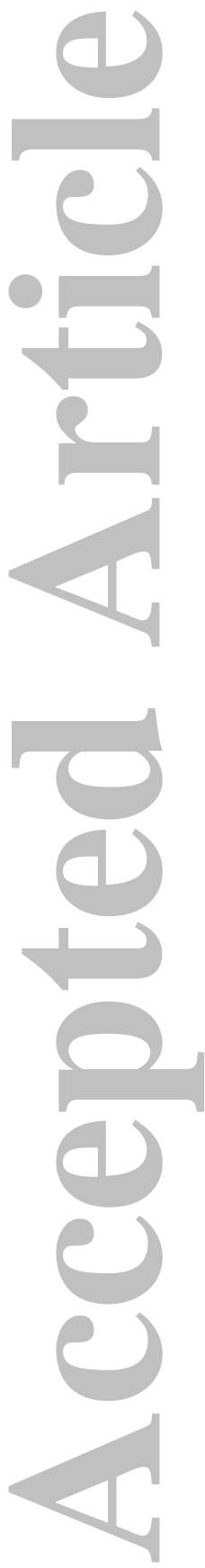

This article is protected by copyright. All rights reserved. 


\section{M(V) Curve: Total Phosphorus}

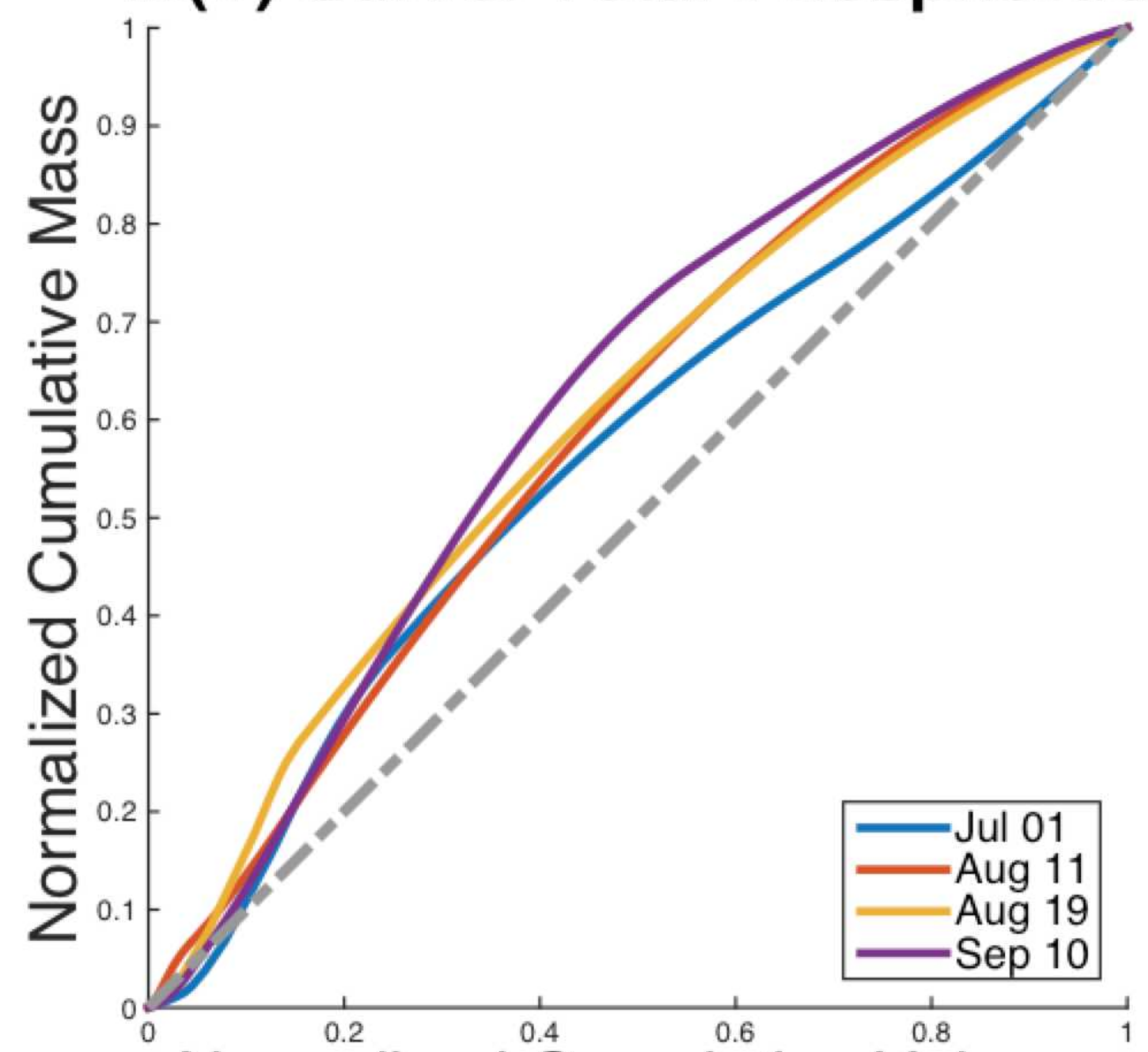

M(V) Curve: TSS

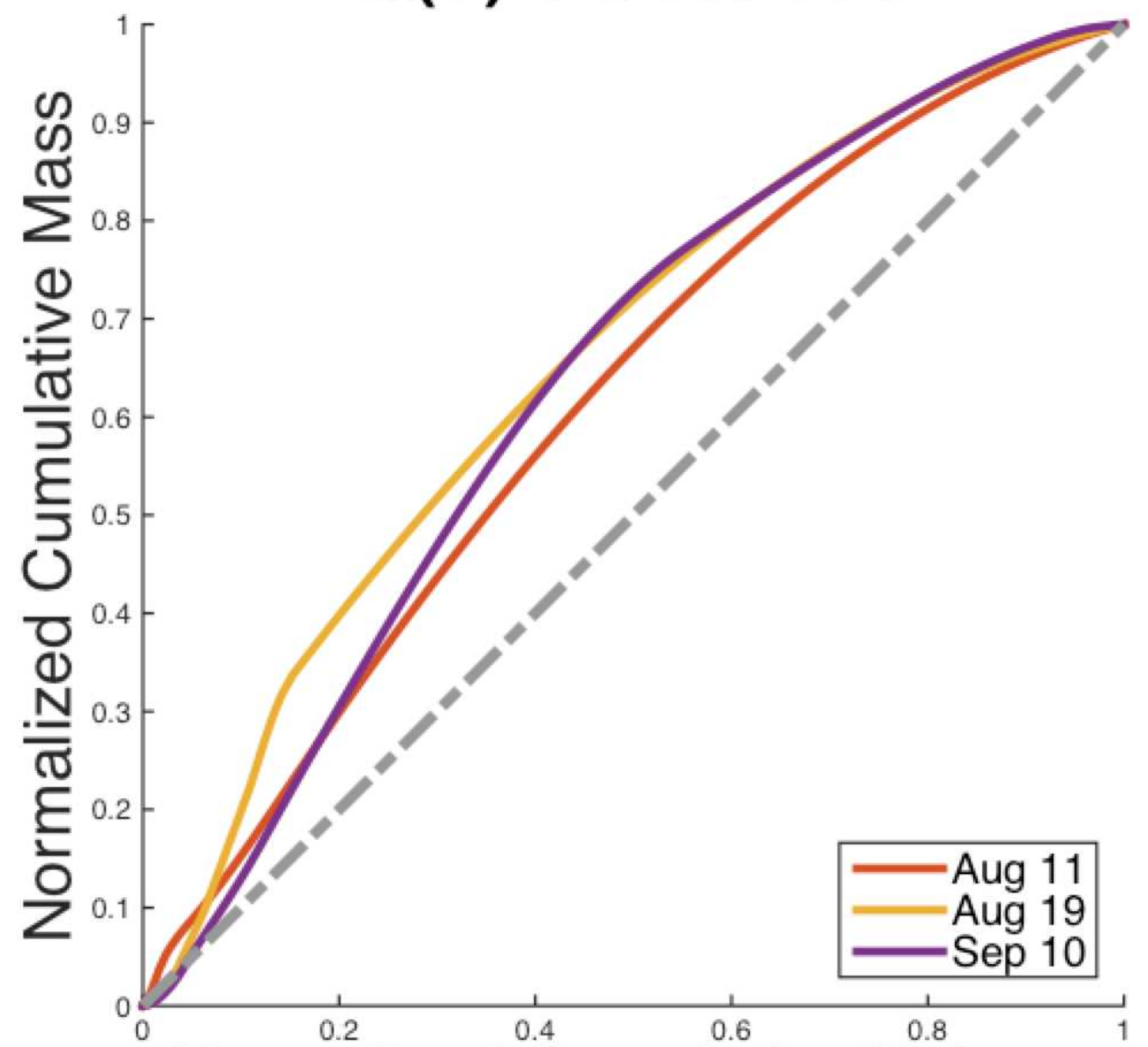

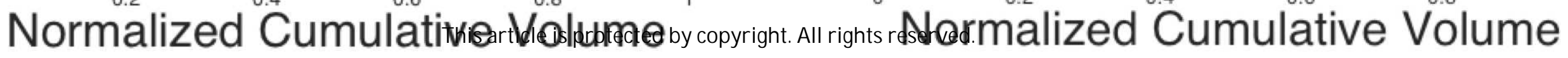

